\title{
A taxonomic review of the Afrotropical genus Dragmatucha Meyrick, 1908 (Lepidoptera, Gelechioidea, Lecithoceridae, Torodorinae), with descriptions of eleven new species
}

\author{
KYU-TEK PARK ${ }^{1}$, JUN-MO KOO², DAVID J. L. AGASSIZ³ \& LEIF AARVIK ${ }^{4, *}$ \\ ${ }^{1}$ Bioresource and Environmental Center, Division of Life Sciences, Incheon National University, Incheon, 22012 Korea \\ "ktpark02@gmail.com; ○ https://orcid.org/0000-0001-9933-4497 \\ ${ }^{2}$ Department of Plant Medicine, Chungbuk National University, Cheongju, 28644 Korea. \\ =taran@9539@gmail.com; 나ttps://orcid.org/0000-0003-2639-6456 \\ ${ }^{3}$ Dept. of Life Sciences, Insects Division, Natural History Museum, London SW7 5BD, UK. \\ ”=david.agassiz@gmail.com; @ https://orcid.org/0000-0002-4300-8067 \\ ${ }^{4}$ Natural History Museum, University of Oslo, P.O. Box 1172 Blindern, NO-0318 Oslo, Norway. \\ "lleif.aarvik@nhm.uio.no; @ https://orcid.org/0000-0002-0112-8837 \\ ${ }^{*}$ Corresponding author
}

\begin{abstract}
The genus Dragmatucha Meyrick is reviewed and 11 species of a total of 13 are described as new. The new species originate from the Democratic Republic of Congo, Ghana, Kenya, and Uganda. Based on morphological characters, especially the color pattern of both wings, the genus is divided into two species-groups: the proaula species-group with five species (D. proaula Meyrick, 1908; D. galbinea Park, sp. nov.; D. kabarolensis Park, sp. nov.; D. saltualis Park, sp. nov. and D. vittatella Park, sp. nov.) and the hispidula species-group with eight species (D. hispidula Park, 2018; D. goniotes Park, sp. nov.; D. cochliana Park, sp. nov.; D. pedalis Park, sp. nov.; D. ghanaensis Park, sp. nov.; D. crinifrutalis Park, sp. nov.; D. dizostera Park, sp. nov. and D. kakumensis Park, sp. nov.). Adults and male genitalia of all new species are illustrated, but female genitalia are provided only for D. ghanaensis Park, sp. nov. and D. kakumensis Park, sp. nov. When fresh material was available, the analysis of COI sequences was undertaken.
\end{abstract}

Key words: Democratic Republic of Congo, Ghana, Idiopteryx, Kenya, morphology, taxonomy, Uganda

\section{Introduction}

The genus Dragmatucha Meyrick, 1908, an Afrotropical genus belonging to the subfamily Torodorinae (Gelechioidea: Lecithoceridae), was established as monotypic based on D. proaula Meyrick, 1908 from South Africa. The second known species is D. hispidula Park, 2018 described from Cameroon. Further distributional data for D. proaula Meyrick was summarized by Park \& De Prins (2019): South Africa (Meyrick 1908), Botswana and Mozambique (Pinhey 1975), Namibia and Zimbabwe (Janse 1954), and Kenya (Park \& De Prins 2019). The genus is characterized by the forewing venation with $\mathrm{M}_{3}$ entirely merged with $\mathrm{CuA}_{1}, 1 \mathrm{~A}+2 \mathrm{~A}$ not forked at base; the hind wing with well-developed CuP; and the hind tibia roughly tufted with long, piliform scales (Park \& De Prins 2019). The genus is related to another Afrotropical genus, Idiopteryx Walsingham, 1891, which was also described from South Africa, based on the type species only, I. obliquella (Walsingham, 1881), sharing with Dragmatucha similarities in the male genitalia. The four known species of Idiopteryx were enumerated by Park \& De Prins (2019). Dragmatucha is distinguished from Idiopteryx by the forewing venation with $\mathrm{M}_{3}$ coincident with $\mathrm{Cu} \mathrm{A}_{1}$, whereas in Idiopteryx $\mathrm{M}_{3}$ is present and on a common stalk with $\mathrm{CuA}_{1}$ and $\mathrm{CuA}_{2}$. Due to the different forewing venation, Dragmatucha has been treated as full genus separate from Idiopteryx. However, further study based on DNA sequencing is required to clarify the relationship between these two genera. Hopefully, in the future, additional fresh material will become available.

In the present study, 13 Afrotropical species of Dragmatucha are reviewed, 11 of which are described as new 
to science. Based on morphological characters, especially the color pattern of both wings, all species are placed in two species-groups; the proaula species-group and the hispidula species-group. To support the species level status, the DNA sequences are provided for those species of which fresh material is available. The order of species in each group is based on morphological similarity.

\section{Material and methods}

The present study is based on the loan material from the Natural History Museum, University of Oslo (NHMO), Oslo, Norway, collected in Uganda by Leif Aarvik; Natural History Museum (Museum für Naturkunde) (MfN), Berlin, Germany, collected by Wolfram Mey in Uganda in 2014; Carnegie Museum of Natural History (CMNH), Pittsburgh, USA collected by H. L. Weber in Cameroon in 1917; Royal Museum for Central Africa (RMCA), Tervuren, Belgium, collected in Democratic Republic of the Congo (here treated as DR Congo) by J. Ghesquière in 1936; and partly from David Agassiz's personal collection collected in Ghana, Uganda, and Kenya in 2011-2016. Preparation of the genitalia and the wing slides follows Park et al. (2019). For descriptions, the wingspan was measured from the apex of the left wing to the apex of the right wing. The color standard for the descriptions of adults follows Kornerup \& Wanscher (1978). Tissue samples were obtained from single legs of adults. DNA extraction, PCR for COI barcodes, and sequence alignment follow Park et al. (2019). The COI barcode sequences were obtained for nine of 13 species of Dragmatucha and the sequence log number (CBNU-\#) to match the specimen sequenced are listed. An appendix for them is attached.

The depositories of the types are abbreviated as follows:

CMNH: Carnegie Museum of Natural History, Pittsburgh, Pennsylvania, USA.

MfN: Natural History Museum (Museum für Naturkunde), Berlin, Germany.

NHMO: The Natural History Museum, University of Oslo, Oslo, Norway.

NHMUK: Natural History Museum, London, UK.

RMCA: Royal Museum for Central Africa, Tervuren.

TMSA: Ditsong National Museum of Natural History (= former Transvaal Museum), Pretoria, Republic of South Africa.

\section{Systematic accounts}

\section{Genus Dragmatucha Meyrick, 1908}

Dragmatucha Meyrick, 1908: 726. Type species: Dragmatucha proaula Meyrick, 1908. Type locality: South Africa.

The genus Dragmatucha is superficially similar to Idiopteryx, but it can be distinguished by the forewing venation with $\mathrm{M}_{3}$ coincident with $\mathrm{CuA}_{1}$. Re-description for venation and hind tibia are as follows: antenna as long as forewing or slightly shorter, finely ciliate; forewing with $R_{3}$ stalked with $R_{4+5}, R_{5}$ to costa, $M_{2}$ well-developed, $M_{3}$ entirely merged with $\mathrm{CuA}_{1} ; \mathrm{CuA}_{1}+\mathrm{CuA}_{2}$ short-stalked, $1 \mathrm{~A}+2 \mathrm{~A}$ not forked at base; hind wing with $\mathrm{M}_{2}$ well-developed, $\mathrm{M}_{3}$ entirely merged with $\mathrm{CuA}_{1}$, Cup well-developed, arising from before middle of lower margin of discal cell or often freely arising from near base; hind tibia roughly tufted with long piliform scales.

\section{Key to the species groups, based on wing pattern}

1. Forewing with usually broad yellowish white antemedian band, and postmedian band present or absent; hind wing evenly col-

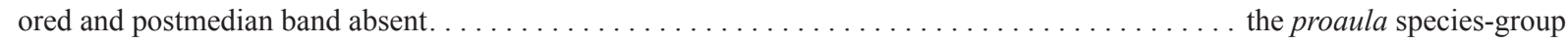
Forewing with narrow, yellowish white antemedian band and various markings present in distal area; hind wing usually concolorous with forewing ground color or paler, usually postmedian band well-developed. . . . . . . the hispidula species-group 


\section{The proaula species-group}

\section{Dragmatucha proaula Meyrick, 1908}

(Figs 1A-E)

Dragmatucha proaula Meyrick, 1908: 726; Janse, 1954: 381. Type locality: South Africa, North Transvaal, Limpopo. Type specimen: Holotype 19 , TMSA.

Idiopteryx proaula; Meyrick, 1925: 227.

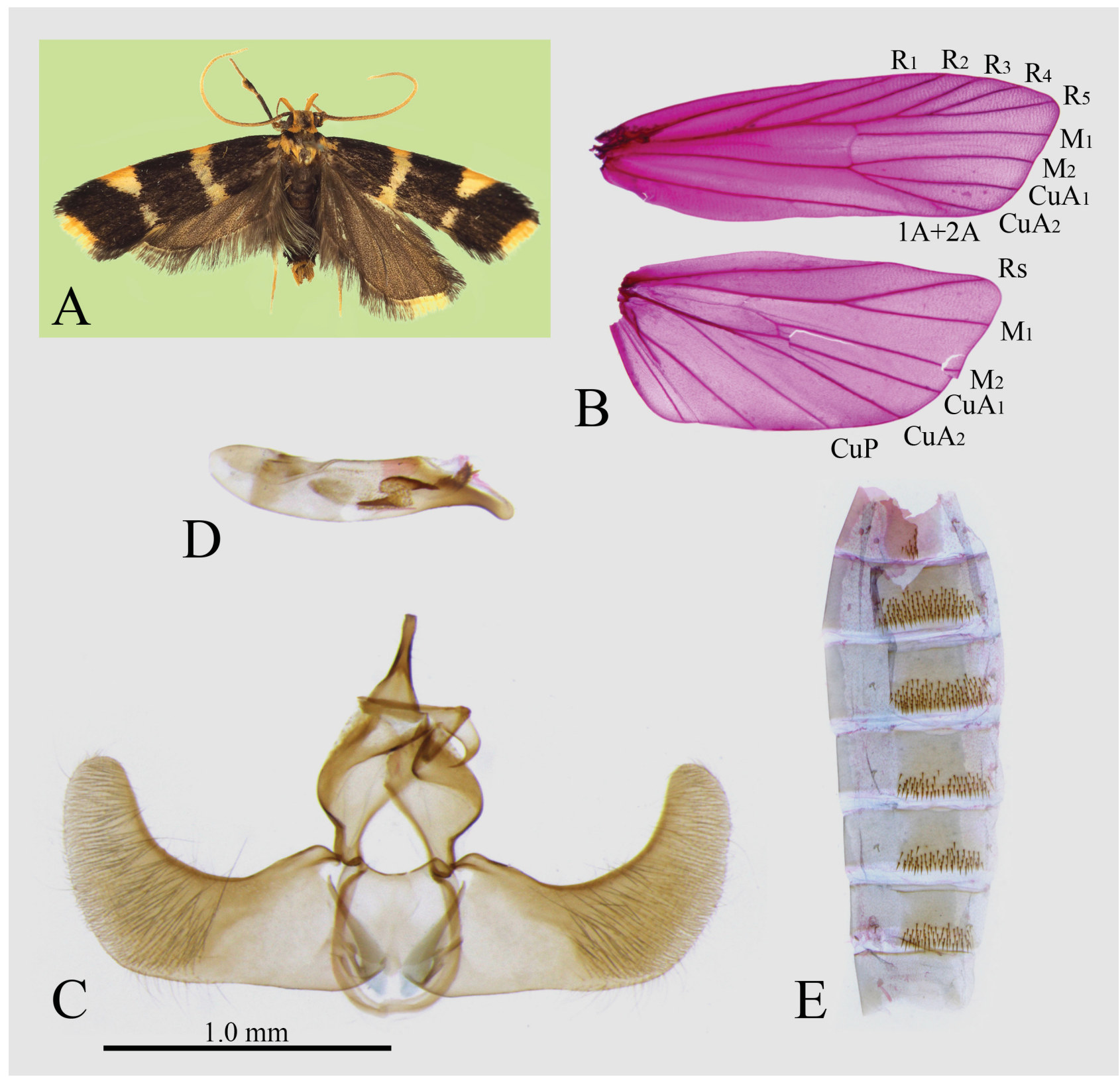

FIGURE 1. Dragmatucha proaula Meyrick: A, adult, from Kenya; B, venation, wing slide no. CIS-7138; C, male genitalia, gen. slide no. CIS-7183; D, ditto, aedeagus; E, abdomen with spinous zones.

Material examined. Kenya: $3 \hat{\jmath}$, Central, Aberdare C., Club 6000 ft, 1 iv 2000, 30 v 2000, leg. D.J.L. Agassiz; 1 ภ, same locality, 30 v 2000, in NHMUK; $2 \widehat{\jmath}$, Rift valley, Lake Nakuru Park, 6000 ft, 5 x 1999, leg. D.J.L. Agassiz; $2 \widehat{\jmath}$, Rift Valley, Rumuruti 6000 ft, 31 xii 1999, leg. D.J.L. Agassiz, gen. slide no. CIS-7183; wing slide no. CIS-7138;

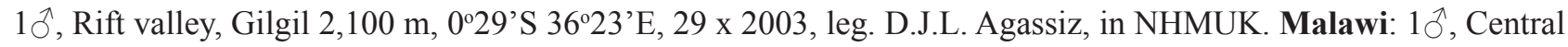
Region, Lilongwe Distr., Dzalanyama Forest Lodge 1,270 m, 15 ii 2004, leg. L. Aarvik, in NHMO. South Africa: more than 30 additional specimens from South Africa in TMSA, including 1ภ, Pretoria, 25 ix 1914, A.J.T. Janse, 


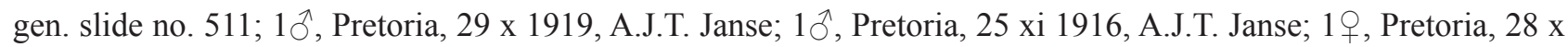
1925, A.J.T. Janse, gen. slide no. 5491; and 1우, Warmbath, 15 v 1953, A.J.T. Janse, in TMSA.

Diagnosis. Wingspan $23.0-27.0 \mathrm{~mm}$. The species is characterized by the forewing with well developed orange antemedian and postmedian bands, and with orange fringes from below apex to above tornus.

Re-description. Venation (Fig. 1B). Forewing with $\mathrm{R}_{1}$ arising from near middle of discal cell; $\mathrm{R}_{3}$ stalked with $R_{4+5}$ for basal $1 / 4 ; R_{4}$ and $R_{5}$ stalked for about basal $3 / 5, R_{5}$ reaching costa; $M_{1}$ remote from $R_{3+4}$ at base; $M_{2}$ approximate to $\mathrm{CuA}_{1}$, nearly parallel to $\mathrm{M}_{1} ; \mathrm{M}_{3}$ entirely merged with $\mathrm{CuA}_{1} ; \mathrm{CuA}_{1}$ short-stalked with $\mathrm{CuA}_{2} ; 1 \mathrm{~A}+2 \mathrm{~A}$ not forked at base; cell closed; hind wing with $\mathrm{M}_{2}$ well developed; $\mathrm{M}_{3}$ entirely merged with $\mathrm{CuA}_{1}$; $\mathrm{CuP}$ well developed, arising from middle of lower margin of discal cell.

Male genitalia (Figs 1C, D): See Janse (1954, pl. 165, Fig. 4- line drawing; pl. 173, Fig. 2- photos); Park \& De Prins (2019, Figs 8A, B). Uncus narrowly elongate. Valva with deeply concave costal margin and strongly upturned distally. Juxta with slightly concave caudal margin. Aedeagus narrowly produced apically, with round apex.

Female genitalia. See Janse (1954, pl. 167, Fig. 1).

Distribution. Botswana (Pinhey 1975); Kenya (Park \& De Prins 2019); Malawi (present paper); Mozambique (Pinhey 1975); Namibia (Janse 1954); South Africa (Meyrick 1908); Zimbabwe (Janse 1954).

\section{Dragmatucha kabarolensis Park, sp. nov.}

(Figs $2 \mathrm{~A}-\mathrm{G}$ )

Type material. Holotype: male, Uganda, W. Kabarole Distr., Ruwenzori Mts., Nyakalengija, 0²0'994“N 3001'820“E, 1,700 m, 10-11 xi 2007, leg. L. Aarvik \& M. Fibiger; gen. slide no. CIS-7193; wing slide no. CIS-7469;

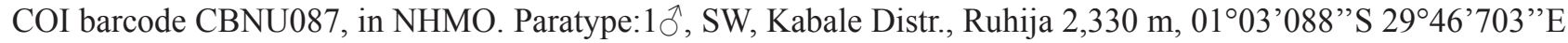
, 4-7 xi 2007, leg. L. Aarvik \& M. Fibiger; gen. slide no. CIS-7460, in NHMO.

Diagnosis. This species can be distinguished from the next new species D. galbinea sp. nov., by the forewing which has the orange-white antemedian band strongly broadened toward costa in the anterior half, and a small orange-white costal patch, a remnant of the postmedian band; the hind wing evenly orange white. The male genitalia can be distinguished from those of $D$. galbinea sp. nov. by the cucullus without median ridge.

Description. Male (Fig. 2A). Wingspan $21.0 \mathrm{~mm}$. Head: Pale orange dorsally. Antenna as long as forewing; basal segment elongated, broadened distally, pale orange dorso-anteriorly and dark brown on posterior surface; flagellum pale orange throughout, without distinct annulations, finely ciliate. Second palpomere of labial palpus thickened, arched, fuscous in basal 1/3, then yellowish brown on outer surface, yellowish white on inner surface; $3^{\text {rd }}$ palpomere slender, strongly upturned, as long as $2^{\text {nd }}$ palpomere. Thorax: Tegula pale orange; thorax pale orange, speckled with dark-brown scales anteriorly. Hind tibia roughly scaled with yellowish- brown setae on inner surface medially; orange white on outer surface. Forewing ground color dark yellowish brown; antemedian band yellowish white, broadened toward costa, width on costa more than twice width on dorsum, postmedian band not developed; costa slightly arched beyond basal $2 / 3$, with small, triangular, orange-white costal patch on 3/4 of costa; apex acute; termen oblique; fringe with narrow, yellowish white basal line, then dark yellowish brown medially, yellowish white in distal half; venation (Fig. 2C) similar to that of the type species. Hind wing evenly yellowish white; apex more or less obtuse; venation also similar to that of the type species. Abdomen (Fig. 2G): Spinous zones on dorsal surface broadly developed with strong spines; sternite VIII concave antero-medially.

Male genitalia (Figs 2D-F): Uncus slender, heavily sclerotized, slightly bent beyond 4/5, not exceeding apex of basal plate of gnathos, acute apically. Basal plate of gnathos narrowed in distal half; median process short, strongly bent beyond middle, with sharply pointed apex. Tegumen sclerotized, with deeply concave anterior margin. Valva broad basally; costa with basal expansion anteriorly, deeply concave beyond; ventral margin nearly straight, slightly concave before cucullus; sacculus weakly sclerotized, triangular in basal 1/3; cucullus short, densely setose, with rounded outer margin, triangularly produced apically; apex sharply pointed, bent inwardly. Juxta trapezoidal, narrowed distally, with crescent median plate on caudal margin; anterior margin with conic protrusion medially. Aedeagus stout, slightly shorter than valva, gently bent medially; dorsal surface terminated with semi-ovate protrusion, slightly upturned; cornuti consist of a round plate and an irregularly shaped, small plate apically.

Female unknown.

Distribution. Uganda (Kabarole and Kabale districts).

Etymology. This species' name is derived from the type locality. 


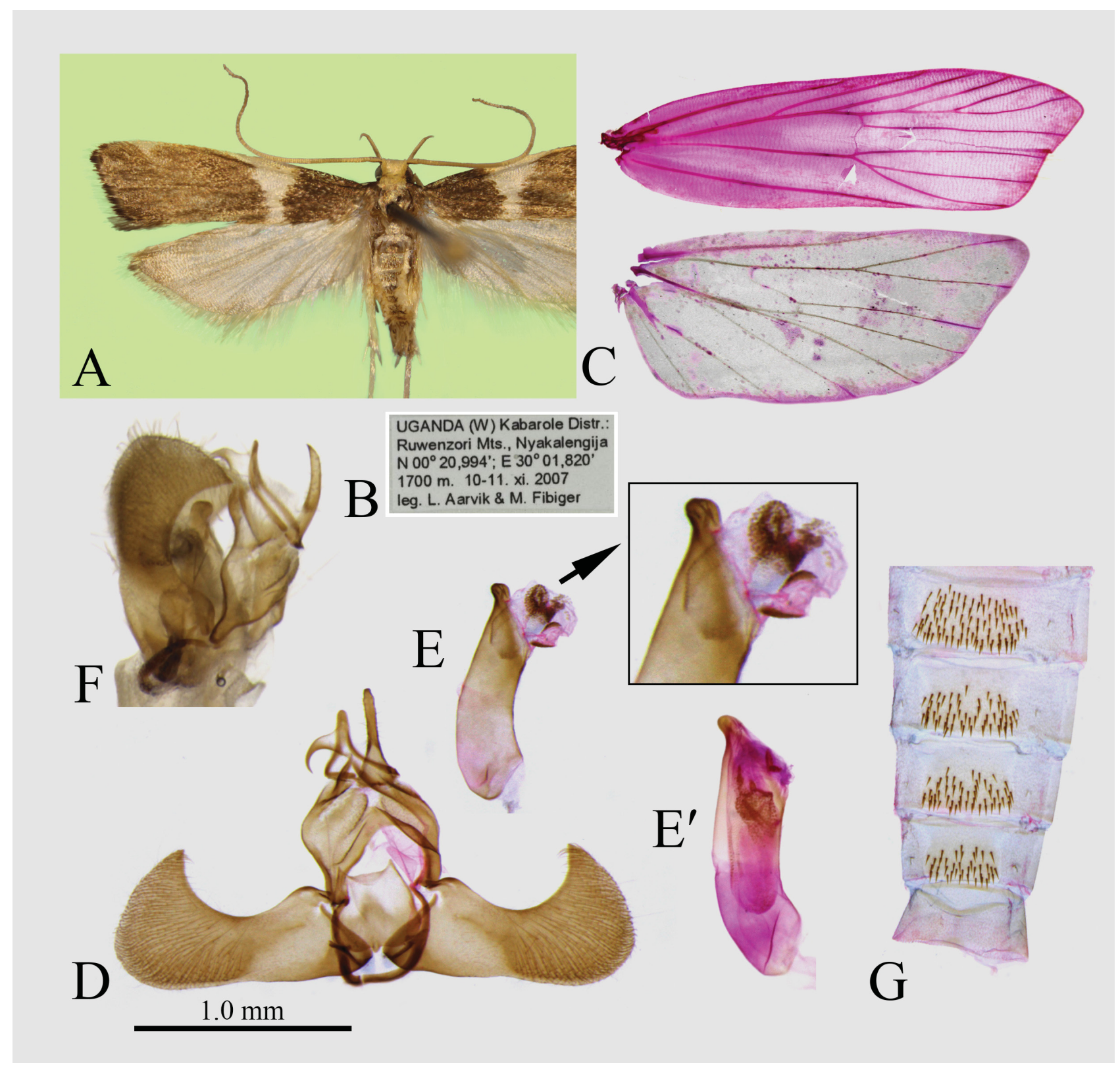

FIGURE 2. Dragmatucha kabarolensis Park, sp. nov.: A, adult, holotype; B, label; C, venation, wing slide no. CIS-7469; D, male genitalia, holotype, gen. slide no. CIS-7193; E, ditto, aedeagus, with close-up apical part; E', aedeagus, paratype, gen. slide no. CIS-7460; F, lateral view of male genitalia; G, abdomen with spinous zones, holotype.

\section{Dragmatucha galbinea Park, sp. nov.}

(Figs 3A-H)

Type material. Holotype: male, Uganda, Kasese Distr., Kibale Nat. Park, 19-24 xi 2014 [UTM:] 36N TF 0582 6208, 1,500 m, Leif Aarvik \& Knud Larsen; gen. slide no. CIS-7190; COI barcode CBNU084, in NHMO. Paratype: $10^{\top}$, Western, Kibale Forest, Kanyawara 1,520 m, 0³3'39"N 30²1'27"E, 22 x 2014, leg. D.J.L. Agassiz; gen. slide no. CIS-7189, in NHMUK.

Diagnosis. This species is superficially similar to $D$. saltualis $\mathbf{s p . ~ n o v . , ~ b u t ~ i t ~ c a n ~ b e ~ d i s t i n g u i s h e d ~ f r o m ~ t h e ~ l a t t e r ~}$ by the postmedian band missing or poorly developed on the forewing; and the male genitalia with sharply produced apex of the cucullus, and juxta with heavily sclerotized median process on the caudal margin. It is also differentiated by the DNA sequence data using COI barcode (with 12.6\% distance between them). 


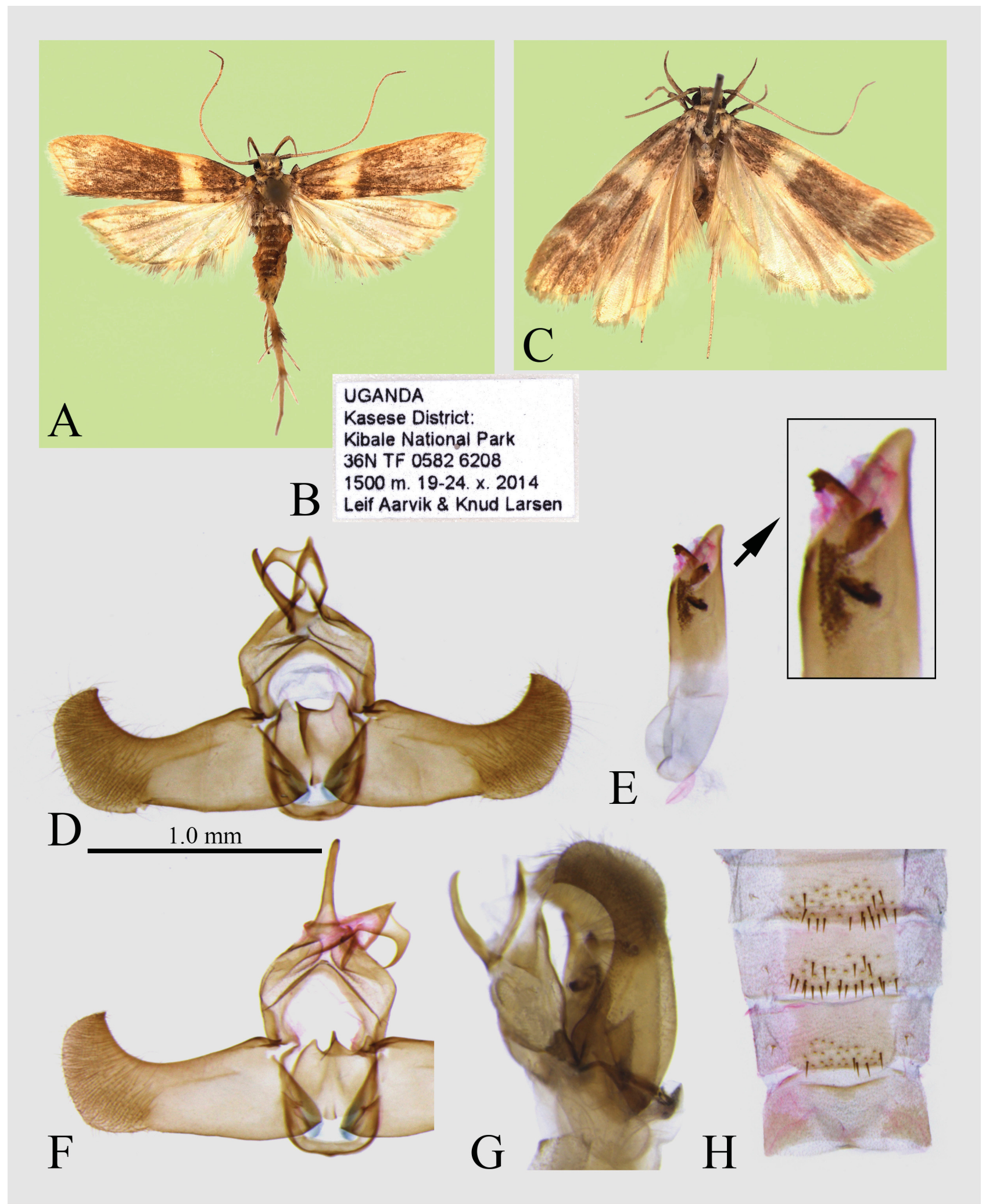

FIGURE 3. Dragmatucha galbinea Park, sp. nov.: A, adult, holotype; B, label; C, adult, paratype; D, male genitalia, holotype, gen. slide no. CIS-7190; E, aedeagus, with close-up apical part, paratype, gen. slide no. CIS-7188; F, ditto, left side of male genitalia, paratype, gen. slide no. CIS-7188; G, ditto, lateral view; H, abdomen with spinous zones, holotype.

Description. Male (Figs 3A, C). Wingspan $19.0 \mathrm{~mm}$. Head: Covered with yellowish white appressed scales dorsally. Antenna slightly shorter than forewing; basal segment elongated, broadened distally, dark brown dorsally and yellowish white ventrally; flagellum pale yellow throughout, without distinct annulations, finely ciliate. Second 
palpomere of labial palpus thickened, arched, yellowish brown on outer surface, yellowish white on inner surface; $3^{\text {rd }}$ palpomere slender, strongly upturned, as long as $2^{\text {nd }}$ palpomere. Thorax: Tegula yellowish brown, covered with dark brown scales in anterior 1/3; thorax also yellowish white, covered with dark brown scales anteriorly. Hind tibia roughly scaled dorsally with strong setae medially; yellowish white on outer surface. Forewing ground color yellowish brown, with well- developed, rectangular, yellowish white antemedian band; postmedian band zigzagged or invisible; costa nearly straight, oblique beyond 2/3; apex more or less obtuse; termen slightly concave beyond apex; venation similar to that of the preceding species. Hind wing evenly yellowish white, venation also similar to that of the preceding species. Abdomen (Fig. 3H): Spinous zone on dorsal surface with strong spines; sternite VIII not modified.

Male genitalia (Figs 3D-G): Uncus elongate, slender, as long as length of tegumen, slightly exceeding apex of basal plate of gnathos. Basal plate of gnathos triangularly acute at apex; median process rather short, broad basally, strongly bent beyond 2/3, with sharply pointed apex. Tegumen weakly sclerotized, rather short, deeply concave on anterior margin. Valva broad, elongated; costa slightly expanded near base, then oblique; ventral margin slightly convex medially; cucullus foot-shaped, densely setose, with acute apex. Juxta with heavily sclerotized, triangular median process on caudal margin, vertically ridged centrally. Aedeagus stout, longer than uncus + tegumen, produced apically; cornuti consist of three patches of spinules in distal part.

Female unknown.

Distribution. Uganda (Kibale Nat. Park).

Etymology. This species name is derived from the Latin, galbinus (= yellow) with a Latin adjective suffix, inea, referring to the yellowish white band on the forewing.

\section{Dragmatucha saltualis Park, sp. nov.}

(Figs 4A-F)

Type material. Holotype: male, Kenya, Central, Castle Forest Lodge, $0^{\circ} 22^{\prime} 51^{\prime \prime} \mathrm{S} 37^{\circ} 18^{\prime} 35^{\prime \prime} \mathrm{E}, 2,050 \mathrm{~m}, 28$ x 2016 , leg. D.J.L. Agassiz \& K. Larsen; gen. slide no. CIS-7191; COI Barcode CBNU088, in NHMUK.

Diagnosis. This species is superficially similar to $D$. galbinea Park, sp. nov., but it can be distinguished from the latter by the forewing with well-developed, orange-white postmedian band present, and the male genitalia differ from the two preceding new species with very elongated valva and the juxta rounded on caudal margin.

Description. Male (Fig. 4A). Wingspan $22.0 \mathrm{~mm}$. Head: Pale yellow dorsally. Antenna about 2/3 of forewing; basal segment elongated, pale yellow all around; flagellum pale yellow throughout, without distinct annulations, finely ciliate. Second palpomere of labial palpus thickened, arched, shiny, pale yellow all around; $3^{\text {rd }}$ palpomere slender, strongly upturned, as long as $2^{\text {nd }}$ palpomere, pale yellow. Thorax: Tegula pale yellow, with fuscous scales anteriorly; thorax pale yellow dorsally. Hind tibia roughly scaled with pale yellowish, strong setae dorsally; yellowish white on outer surface. Forewing ground color pale greyish orange; antemedian band yellowish white, slightly broadened toward costa; postmedian band well-developed, orange-white, zigzagged, slightly broader in anterior half; costa slightly arched in basal $1 / 3$, then nearly straight, slightly oblique beyond $3 / 4$; apex obtuse; termen oblique; fringe paler in basal $1 / 3$, then concolorous with ground color. Hind wing evenly yellowish white. Abdomen (Fig. 4F): Spinous zones sparsely set with strong spines; tergite VIII with narrowly widened sclerite along posterior margin; sternite VIII not specifically modified.

Male genitalia (Figs 4C-E): Uncus extremely elongate, parallel sided, gently bent medially, reaching apex of basal plate of gnathos, apex acute. Basal plate of gnathos large, with long basal arms, narrowed apically; median process short, bent beyond middle, with sharply pointed apex. Tegumen sclerotized, with roundly concave anterior margin. Valva extremely elongated, with arched cucullus; costa with small basal expansion anteriorly, then concave; ventral margin slightly concave basally; sacculus weakly developed, nearly invisible; cucullus elongated, densely setose, with arched outer margin, with round apex. Juxta with rounded caudal margin, weakly sclerotized along caudal margin. Vinculum narrowly banded. Aedeagus more or less slender, shorter than valva, apical protrusion of dorsal surface ladle-like, upturned.

Female unknown.

Distribution. Kenya (Central).

Etymology. This species name is derived from the Latin, saltus (= forest, woodland), with a Latin suffix, -alis, referring to the collecting site of the forest. 


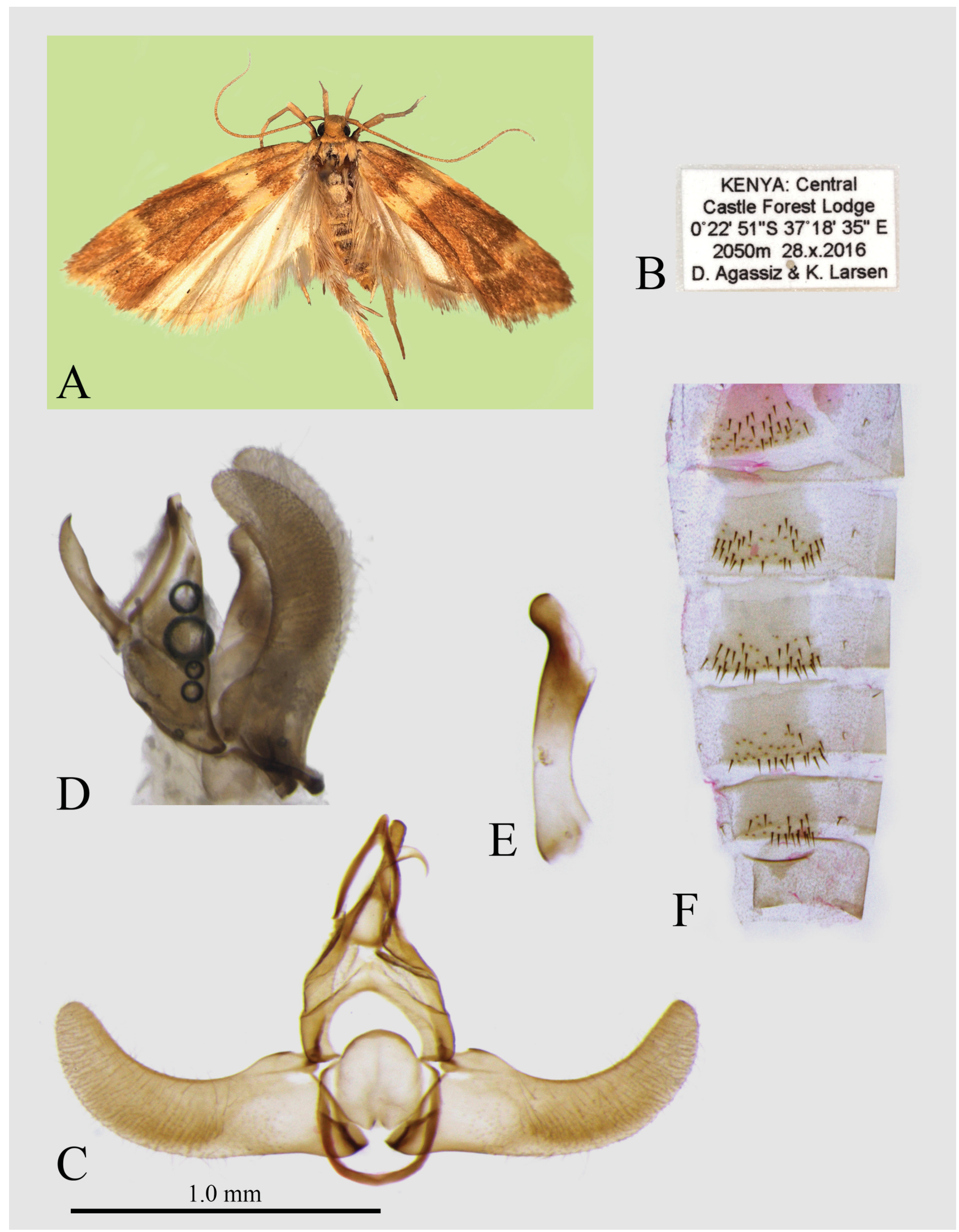

FIGURE 4. Dragmatucha saltualis Park, sp. nov.: A, adult, holotype; B, label; C, male genitalia, holotype, gen. slide no. CIS7191; D, ditto, lateral view; E, aedeagus; F, abdomen with spinous zones. 
5. Dragmatucha vittatella Park, sp. nov.

(Figs 5A-G)

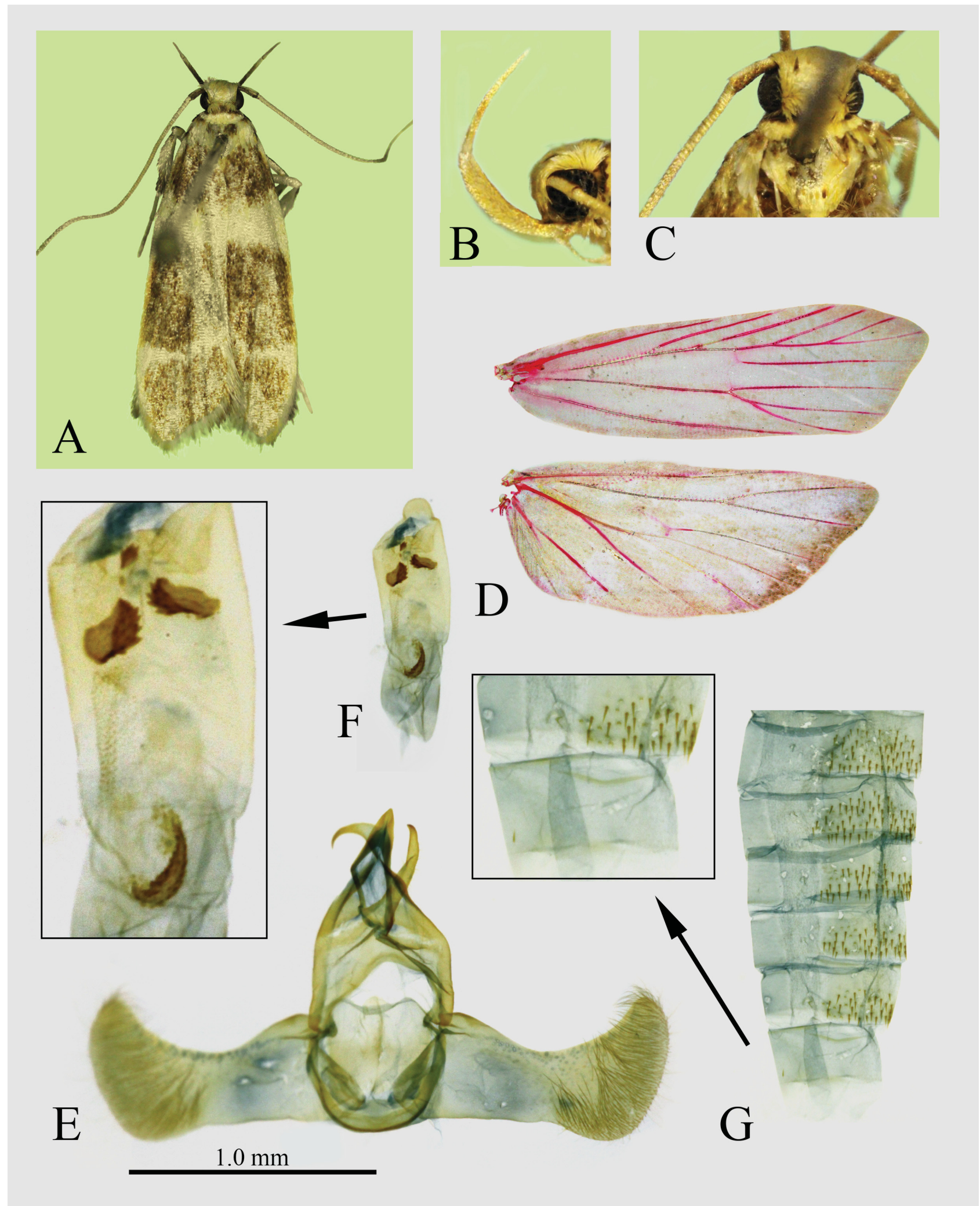

FIGURE 5. Dragmatucha vittatella Park, sp. nov.: A, adult, holotype; B, labial palpus; C, dorsal view of head and thorax; D, venation, wing slide no. CIS-7046; E, male genitalia, holotype, gen. slide no. CIS-7008; F, ditto, aedeagus, with close-up cornuti; G, abdomen with spinous zones. 
Type material. Holotype: male, Uganda, Kibale Nat. Park, Biol. Field Station, 19-24 xi 2014, LF leg. W. Mey; gen. slide no. CIS-7008. Paratypes: 7ð̄, same data as holotype; wing slide no. CIS-7046; COI barcode CUNBCBNU018 \& CBNU065, in MfN.

Diagnosis. The new species can be distinguished from all the preceding new species by the dark yellowish brown forewing ground color with very broad, yellowish white antemedian band, and in the male genitalia it can also be distinguished by the sub-triangular cucullus with nearly straight outer margin.

Description. Male (Figs 5A-D). Wingspan 17.5-19.0 mm. Head: Covered with pale yellow, appressed scales dorsally. Antenna shorter than forewing; basal segment elongated, broadened distally, dark brown dorsally and yellowish white ventrally; flagellum pale yellow throughout, without distinct annulations, finely ciliate. Second palpomere of labial palpus thickened, arched, pale yellowish brown on outer surface; $3^{\text {rd }}$ palpomere slender, as long as $2^{\text {nd }}$ palpomere. Thorax: Tegula yellowish white, covered with dark brown scales in anterior $1 / 3$; thorax also yellowish white, covered with dark brown scales anteriorly. Hind tibia with tuft of pale yellowish brown, strong setae medially; yellowish white on outer surface. Forewing with well-developed median area covered with dark yellowish brown scales preceded by broadly banded, yellowish white antemedian band; postmedian band yellowish white, triangularly broadened toward costa in anterior 2/5; costa slightly arched before $1 / 3$ and beyond $2 / 3$; apex slightly produced; termen slightly concave beyond apex; venation (Fig. 5D) as described in the description of the genus. Hind wing yellowish white, covered with yellowish brown scales in apical area and along termen; venation as described for the genus. Abdomen (Fig. 5G): Spinous zones on dorsal surface broad, with dense spines; segment VIII simple, with weakly sclerotized, crescent sclerite dorsally, along posterior margin not modified.

Male genitalia (Figs 5E, F): Uncus elongate, of even width, slightly curved downward, with acute apex, not exceeding apex of basal plate of gnathos. Basal plate of gnathos triangular, with acute caudal apex; median process gently arched dorsally, with sharply pointed apex. Tegumen sclerotized, deeply concave on anterior margin. Valva with costa broadly expanded basally, then concave; ventral margin nearly straight before cucullus; cucullus footshaped, densely setose, narrowed towards apex. Juxta broad, shield-shaped, concave on caudal margin, with vertical ridge centrally. Aedeagus stout, as long as uncus + tegumen, terminated with semi-ovate plate dorsally; cornuti consist of two large, sole-like plates with conic spines along margin and a small ovate one in distal part, and a crescent plate in basal part.

Female unknown.

Distribution. Uganda (Kibale Nat. Park).

Etymology. This species is derived from the Latin, vittatus (= striped) with a Latin diminutive suffix, -ella, referring to the well-developed band in the forewing.

\section{The hispidula species-group}

\section{Dragmatucha hispidula Park, 2018}

(Figs 6A-E)

Dragmatucha hispidula Park, 2018: 1088. Type locality: Cameroon, Efulen. Type specimen: Holotype $\widehat{o}$, in CMNH.

Material examined. $1 \delta^{\Uparrow}$ (holotype), Cameroon, Efulen, H.L. Weber, Acc. C. M. 6122, 15 x 1917; gen. slide no. CIS-6841, in CMP.

Diagnosis. Wingspan $13 \mathrm{~mm}$. This species is distinguished from the previously known species by the unique maculation of the forewing and the hind wing with yellowish white postmedian band (Fig. 6A).

Male genitalia (Figs 6D, E): See Park (2018, Figs 8, 8a).

Distribution. Cameroon (Park 2018).

\section{Dragmatucha goniotes Park, sp. nov.}

(Figs 7A-H)

Type material. Holotype: male, DR Congo, Musée Du Congo, Eala, vii 1936, leg. J. Ghesquière; gen. slide no. CIS-7187. Paratype: $2{ }^{\lambda}$, same data as holotype; gen. slide no. CIS-7188, in RMCA. 


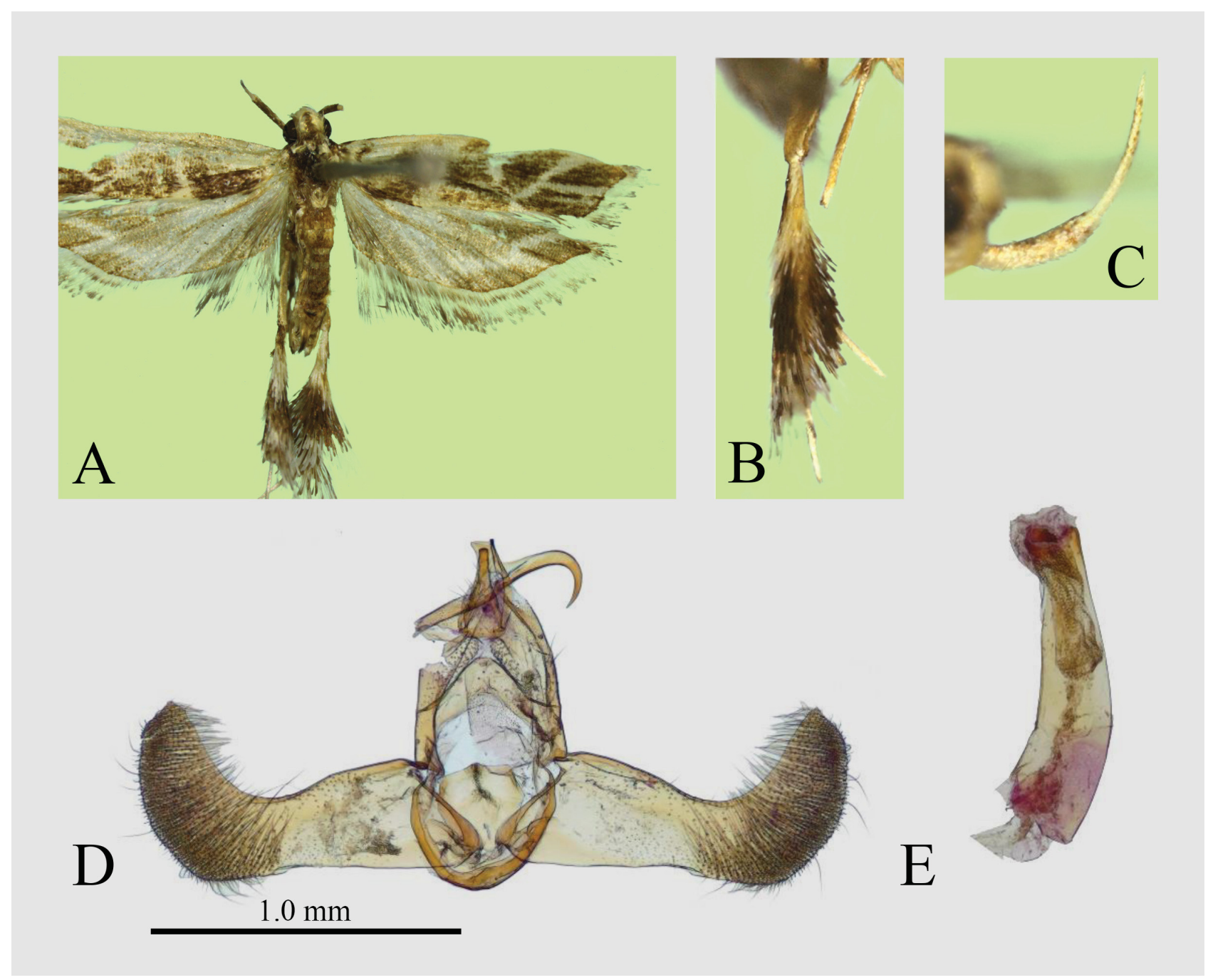

FIGURE 6. Dragmatucha hispidula Park, 2018: A, adult, holotype; B, hind tibia; C, labial palpus, lateral view; D, male genitalia, gen. slide no. CIS-6841; E, aedeagus.

Diagnosis. The new species is superficially similar to the following new species, D. cochliana Park, sp. nov., but it can be distinguished from the latter by the smaller size (via. $18.5 \mathrm{~mm}$ in D. cochliana Park sp. nov.) and the male genitalia with the basal plate of gnathos triangularly developed, the cucullus shorter with nearly straight or slightly convex outer margin, and juxta less concave on caudal margin.

Description. Male (Fig. 7A). Wingspan $16.0 \mathrm{~mm}$. Head: Creamy white anteriorly and yellowish brown posteriorly. Antenna slightly longer than forewing; basal segment elongated, yellowish white dorsally, dark brown on anterior and posterior surface flagellum yellowish white throughout, slightly dilated apically. Second palpomere of labial palpus thickened, long, about twice the width of compound eye, arched, pale yellowish brown on outer surface; yellowish white at apex; $3^{\text {rd }}$ palpomere slender, strongly upturned, shorter than $2^{\text {nd }}$ palpomere, yellowish brown. Thorax: Tegula and thorax mixed with yellowish white and yellowish brown scales. Hind tibia yellowish white, with yellowish brown, rough scales medially. Forewing with broad, dark brown sub-basal area occupying about basal 1/4; antemedian band broad, nearly parallel-sided, yellowish white, slightly broadened anteriorly and posteriorly; postmedian band narrow, yellowish white, zigzagged bellow CuA1; costa slightly arched beyond 3/4, then slightly oblique; apex obtuse; termen oblique; fringe creamy white, with narrow yellowish brown median band. Hind wing ground color yellowish brown; postmedian line well-developed, strongly angled medially; fringe creamy white, with narrow, yellowish-brown median band. Abdomen (Fig. 7H): Spinous zones present on dorsal surface; segment VIII simple.

Male genitalia (Figs 7C-G): Uncus slender, heavily sclerotized, nearly parallel-sided, slightly bent medially, exceeding apex of basal plate of gnathos. Basal plate of gnathos triangularly produced apically; median process 
rather slender, strongly bent from middle, with sharply pointed apex. Tegumen weakly sclerotized, rather short, with deeply concave anterior margin. Valva broad basally, narrowed toward cucullus; costa slightly expanded anteriorly, near base, then slightly oblique; ventral margin convex medially; sacculus weakly sclerotized, broad at base, gradually narrowed, extending to lower corner of cucullus; cucullus strongly curved inwardly beyond $2 / 3$, densely setose; with deeply concave inner margin and nearly straight or slightly convex outer margin. Juxta with triangular caudal lobes laterally; median lobe and central ridge poorly developed. Aedeagus stout, as long as valva, bent at basal 1/3; dorsal surface terminated with semi-ovate protrusion, upturned; cornuti consist of a sole-like plate with conic spines along anterior margin and a large patch bearing numerous spinules.

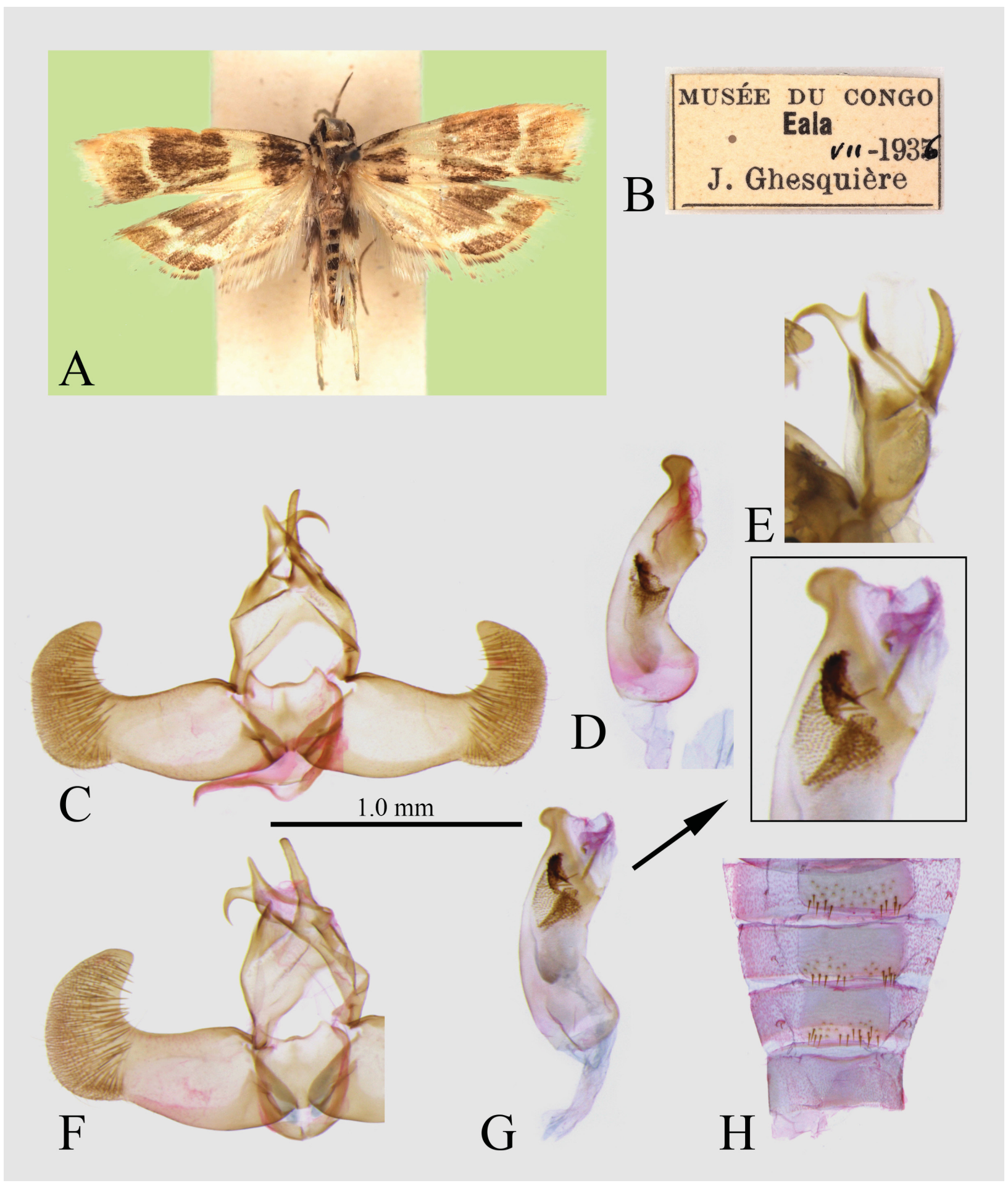

FIGURE 7. Dragmatucha goniotes Park, sp. nov.: A, adult, holotype; B, label; C, male genitalia, holotype, gen. slide no. CIS7187; D, ditto, aedeagus; E, lateral view of uncus+gnathos; F, male genitalia of a paratype, gen. slide no. CIS-7188; G, ditto, aedeagus, with close-up apical part; $\mathrm{H}$, abdomen with spinous zones. 
Female unknown.

Distribution. DR Congo (Eala).

Etymology. This species is derived from the Greek, gonio (= an angle) with a Greek suffix, -tes, referring to the strongly angled postmedian line in the hind wing.

\section{Dragmatucha cochliana Park, sp. nov.}

(Figs 8A-E)

Type material. Holotype: male, Uganda, Kasese Distr., Kibale Nat. Park, 19-24 xi 2014 [UTM:] 36N TF 0582 6208, 1,500 m, Leif Aarvik \& Knud Larsen; gen. slide no. CIS-7192; COI Barcode CBNU083, in NHMO.

Diagnosis. This species is superficially similar to the preceding species, D. goniotes sp. nov., with similar wing pattern of both wings, but it can be distinguished by the larger size, the forewing more narrowly elongated with more oblique termen and the yellowish white postmedian band in the hind wing less sharply angled between veins $\mathrm{R}_{3+4}$ and $\mathrm{M}_{1}$. In addition, it can be distinguished from the latter by the male genitalia with cucullus more robust, half-moon-shaped, with more rounded outer margin; the juxta deeply concave on caudal margin, with triangularly produced latero-caudal lobes.

Description. Male (Fig. 8A). Wingspan $18.5 \mathrm{~mm}$. Head: Yellowish white, with yellowish brown scales posteriorly. Antenna slightly shorter than forewing; basal segment elongated, dark brown dorsally, yellowish white ventrally; flagellum yellowish white throughout, sharply acute apically. Second palpomere of labial palpus thickened, long, more than twice width of compound eye, arched, pale yellowish brown, speckled with dark-brown scales on outer surface; $3^{\text {rd }}$ palpomere slender, strongly upturned, as long as $2^{\text {nd }}$ palpomere, yellowish brown on outer surface. Thorax: Tegula yellowish white, covered with yellowish brown scales anteriorly; thorax yellowish white with yellowish brown scales along anterior margin. Hind tibia yellowish white, with yellowish brown, rough scales medially. Forewing with dark brown sub-basal area; antemedian band broad, band-like, yellowish brown, slightly broadened toward costa and inner margin; area between antemedian band and postmedian band broad, about twice width of basal area; postmedian band linear, strongly angled inwardly on vein $\mathrm{CuA}_{2}$; apex produced; termen oblique; fringe yellowish white, with yellowish brown median band; venation with $\mathrm{R}_{1}$ arising before middle of discal cell; distance between origins of $R_{1}$ and $R_{2}$ about more than twice the length of $R_{2}$ and $R_{3} ; R_{3}$ stalked with $R_{4+5}$ for more than basal $1 / 4 ; R_{4}$ and $R_{5}$ stalked for about basal 3/5, $R_{5}$ reaching costa; $M_{1}$ remote from $R_{3+4}$ at base; $M_{2}$ approximate to $\mathrm{CuA}_{1} ; \mathrm{M}_{3}$ merged to $\mathrm{CuA}_{1} ; \mathrm{CuA}_{1}$ short-stalked with $\mathrm{CuA}_{2} ; 1 \mathrm{~A}+2 \mathrm{~A}$ not forked; cell closed. Hind wing yellowish brown, much paler in basal 1/3; postmedian band similar to that of forewing, slightly angled outwardly on $\mathrm{M}_{2}$; venation with $\mathrm{M}_{2}$ well-developed, arising from near lower corner of cell; $\mathrm{M}_{3}$ merged to $\mathrm{CuA}$; $\mathrm{CuA}$ connate with $\mathrm{CuA}$ basally; CuP well-developed, arising from near middle of lower margin of discal cell. Abdomen (Fig. 8E): Spinous zones on dorsal surface broadly occupied; segment VIII simple.

Male genitalia (Figs 8C, D): Uncus slender, heavily sclerotized, nearly parallel sided, with acute apex, exceeding apex of basal plate of gnathos. Basal plate of gnathos narrowed in apical part, with rounded apex; median process strongly bent beyond middle, with sharply pointed apex. Tegumen sclerotized, deeply concave on anterior margin. Valva broad basally, narrowed toward cucullus; costa convex basally, then slightly oblique; ventral margin arched; sacculus weakly sclerotized, broad at base, then gradually narrowed, terminated at lower corner of cucullus; cucullus short, with rounded outer margin, densely setose. Juxta narrowed distally, concave on caudal margin with triangular caudal lobes laterally; median ridge weakly developed. Aedeagus stout, as long as valva, bent at basal 1/3; dorsal surface terminated with ladle-like plate, upturned; cornuti consist of a sole-like plate and much smaller one, and a large patch bearing numerous spinules in distal part.

Female unknown.

Distribution. Uganda (Kibale Nat. Park).

Etymology. This species is derived from the Latin, cochlear (= ladle, spoon), referring to the ladle-like dorsoapical plate of the aedeagus in the male genitalia, with a Latin suffix, -ana. It is a noun in the nominative case. 


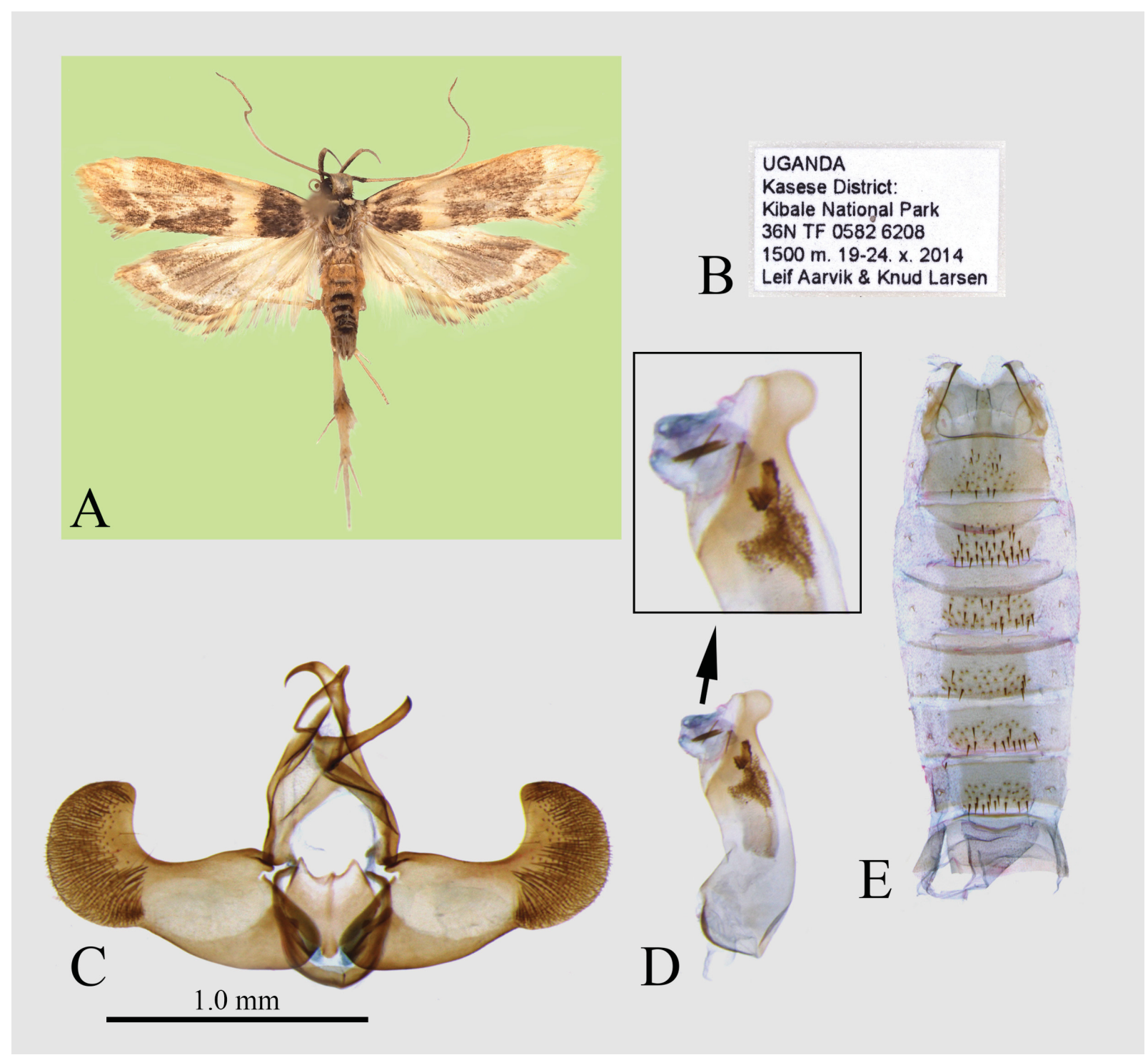

FIGURE 8. Dragmatucha cochliana Park, sp. nov.: A, adult, holotype; B, label; C, male genitalia, holotype, gen. slide no. CIS7192; D, aedeagus, with close-up apical part; E, abdomen with spinous zones.

\section{Dragmatucha pedalis Park, sp. nov.}

(Figs 9A-G)

Type material. Holotype: male, Uganda, Western, Kibale Nat. Park, Kanyawara 1520 m, 0 $0^{\circ} 33^{\prime} 39^{\prime \prime} \mathrm{N} 30^{\circ} 21^{\prime 2} 27^{\prime \prime} \mathrm{E}$, 22 x 2014, leg. D.J.L. Agassiz; gen. slide no. CIS-7186; COI barcode CBNU102. Paratype: $2 \widehat{0}$, same data as holotype; gen. slide no. CIS-7012; wing slide no. CIS-7448; COI Barcode CBNU066 \& - CBNU017, in NHMUK.

Diagnosis. This species can be easily distinguished from all previously described species of the genus by the purplish dark brown ground color of both wings, with narrow, light orange antemedian band, a small, light orange discal spot, an oblique postmedian line, originating from costal patch, discontinued to inner margin, and with subterminal line in the forewing. The male genitalia can be distinguished from its allies by the cucullus elongated with round apex.

Description. Male (Figs 9A-C). Wingspan $14.0 \mathrm{~mm}$. Head: Yellowish brown anteriorly; vertex yellowish brown centrally with yellowish white, erect scales laterally. Antenna slightly shorter than forewing; basal segment elongated, slightly dilated distally, purplish dark brown all around; flagellum yellowish white throughout, without annulations. Second palpomere of labial palpus thickened, arched, yellowish brown in basal half, yellowish white speckled with brownish scales in distal half on outer surface, yellowish white on inner surface; $3^{\text {rd }}$ palpomere slen- 
der, strongly upturned, shorter than $2^{\text {nd }}$ palpomere, yellowish brown on outer surface. Thorax: Tegula yellowish white, with purplish dark brown scales; thorax yellowish white, densely covered with purplish dark brown scales anteriorly and posteriorly. Hind tibia yellowish white in basal half, with yellowish brown, piliform scales above in distal half. Forewing ground color purplish dark brown; with light orange basal streak; antemedian band narrow, light orange, slightly expanded on costa; a small, light orange discal spot present; postmedian line oblique, originating from light-orange costal patch, discontinued to inner margin; subterminal line arising from beyond apex, extended to tornus along termen; costa arched beyond 3/4; apex produced, sharply acute apically; termen oblique; fringe with paler basal line and dark brown median band. Hind wing ground color same as forewing, with broad, yellowish white costal fascia in basal 2/3; postmedian band visible in anterior $1 / 3$; apex sharply produced; fringe concolorous with ground color, with narrow, pale orange basal line and dark brown median band. Abdomen (Fig. 9G): purplish dark brown, with light orange transverse bands on dorsal surface of segments III-VI; spinous zones on dorsal surface more or less sparse spines; tergite VIII with crescent sclerite on anterior margin; sternite VIII broadly convex on posterior margin.

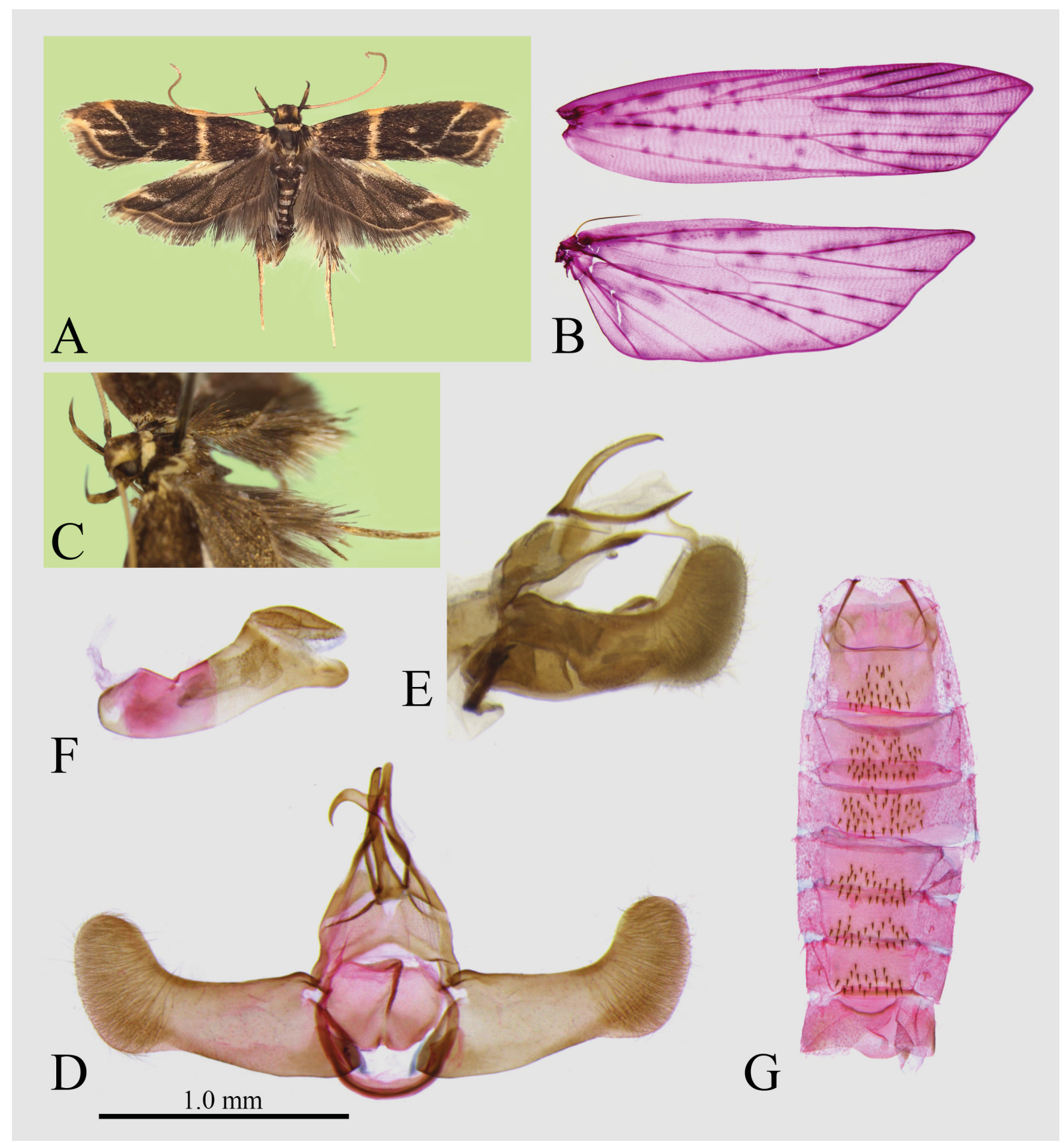

FIGURE 9. Dragmatucha pedalis Park, sp. nov.: A, adult, holotype; B, venation, wing slide no. CIS-7448; C, head and labial palpus; D, male genitalia, gen. slide no. CIS-7186; E, ditto, lateral view; F, aedeagus; G, abdomen with spinous zones. 
Male genitalia (Figs 9D-F): Uncus slender, long, gently bent medially, reaching apex of basal plate of gnathos, acute apically. Basal plate of gnathos narrowed in distal half; median process rather slender, strongly bent beyond middle, with sharply pointed apex. Tegumen sclerotized, deeply concave on anterior margin. Valva elongated, slightly narrowed distally; costa with small basal expansion anteriorly, then nearly straight beyond; ventral margin slightly convex before middle; sacculus weak, nearly invisible; cucullus foot-shaped, with round apex; outer margin slightly arched, densely setose. Juxta broad, shield-shaped, broadened distally, with heavily sclerotized median ridge; anterior margin emarginated at middle. Aedeagus stout, slightly shorter than valva, dilated distally, bifurcated apically; dorsal surface terminated with semi-ovate protrusion; vesica without plate.

Female unknown.

Distribution. Uganda.

Etymology. This species name is derived from the Latin, pedis-(= foot), with a Latin suffix, -alis, referring to the foot-shaped cucullus of the male genitalia.

\section{Dragmatucha ghanaensis Park, sp. nov.}

(Figs 10A-G)

Type material. Holotype: male, Ghana, Central, Kakum N. P. 150 m, 5²0'54"N 1²2'7"W, 19 xi 2011, D.J.L. Agassiz; gen. slide no. CIS-7196; COI Barcode CBNU103. Paratype: 19, same data as holotype; gen. slide no. CIS-7156; wing slide no. CIS-7447; COI Barcode CBNU089, in NHMUK.

Diagnosis. This species is similar to D. hispidula Park, 2018 which was described from Cameroon, by having soot-brown forewing ground color with similar yellowish white bands on the forewing, but it can be distinguished from the latter by having the postmedian band broadly suffused toward costal margin in the forewing; and the male genitalia with pentagonoid basal part of gnathos distally and the aedeagus produced with spatulate apex dorsally.

Description. Male (Figs 10A, B). Wingspan $13.0 \mathrm{~mm}$. Head: Yellowish white, mixed with pale yellowish brown scales centrally. Antenna slightly shorter than forewing; basal segment elongated, black all around; flagellum yellowish white throughout, without annulations, finely ciliate. Second palpomere of labial palpus thickened, arched, dark brown dorsally and on outer surface, yellowish white ventrally; $3^{\text {rd }}$ palpomere slender, strongly upturned, shorter than $2^{\text {nd }}$ palpomere, yellowish white, with some dark brown scales beyond $2 / 3$ dorsally. Thorax: Tegula yellowish brown dorsally, with dark fuscous scales anteriorly; thorax yellowish white dorsally. Hind tibia white in basal $1 / 3$ and roughly scaled with dark yellowish brown, strong setae in distal $2 / 3$ on outer surface; tarsi yellowish white. Forewing ground color soot brown; antemedian band yellowish white, with serrate margins; a small crescent, yellowish white marks followed by oblique, yellowish white streak, extended to postmedian band; postmedian band well-developed, oblique, triangularly broadened in anterior 1/4; costa nearly straight, then slightly oblique beyond 3/4; apex acute; termen oblique; fringe with distinct yellowish white basal line, then concolorous with ground color; venation (Fig. 10B) with $R_{1}$ arising from about basal $2 / 3$ of discal cell; $R_{3}$ stalked with $R_{4+5}$ for basal $1 / 3 ; \mathrm{R}_{5}$ reaching costa; $\mathrm{M}_{2}$ arising from lower corner of discal cell; $\mathrm{M}_{3}$ merged to $\mathrm{CuA} ; \mathrm{CuA}_{1}$ and $\mathrm{CuA}$ short-stalked; $1 \mathrm{~A}+2 \mathrm{~A}$ not forked at base. Hind wing of same color as forewing; postmedian band well-developed, yellowish white; venation with $\mathrm{M}_{2}$ present; $\mathrm{M}_{3}$ entirely merged with $\mathrm{CuA}_{1}$; Cup well-developed, arising near base. Abdomen (Fig. 10F): Spinous zones on dorsal surface sparsely spined; tergite VIII heavily sclerotized, with linear sclerite along anterior margin.

Male genitalia (Figs 10C-E). Uncus elongate, medially bent downward, not reaching apex of basal plate of gnathos. Basal plate of gnathos pentagonal in distal part; median process large, strongly bent beyond middle, with sharply pointed apex. Tegumen weakly sclerotized, with concave anterior margin. Valva broad basally, narrowed toward cucullus; costa convex near base, then oblique; ventral margin nearly straight; sacculus weakly developed; cucullus with rounded outer margin, densely setose; apex acute. Juxta jar-shaped, with a small, triangular median process on caudal margin; latero-caudal lobes nearly undeveloped; median vertical ridge weakly developed. Aedeagus as long as valva, narrowed toward apex; dorsal surface terminated into a small, sclerotized, rake-shaped protrusion; cornutus forming a large sac with minute spinules.

Female genitalia (Figs 10G). Apophyses anteriores about 1/2 length of apophyses posteriores. Antrum membranous, large, cup-shaped. Ductus bursae narrowed in posterior $1 / 5$, then broadened toward corpus bursae, about $1.7 \mathrm{x}$ length of corpus bursae; ductus seminalis arising from nearly end of the broadened part. Corpus bursae large, ovate; signum nearly symmetrical in upper and lower plates, with dense conic spines; median transversal furrow narrow. 

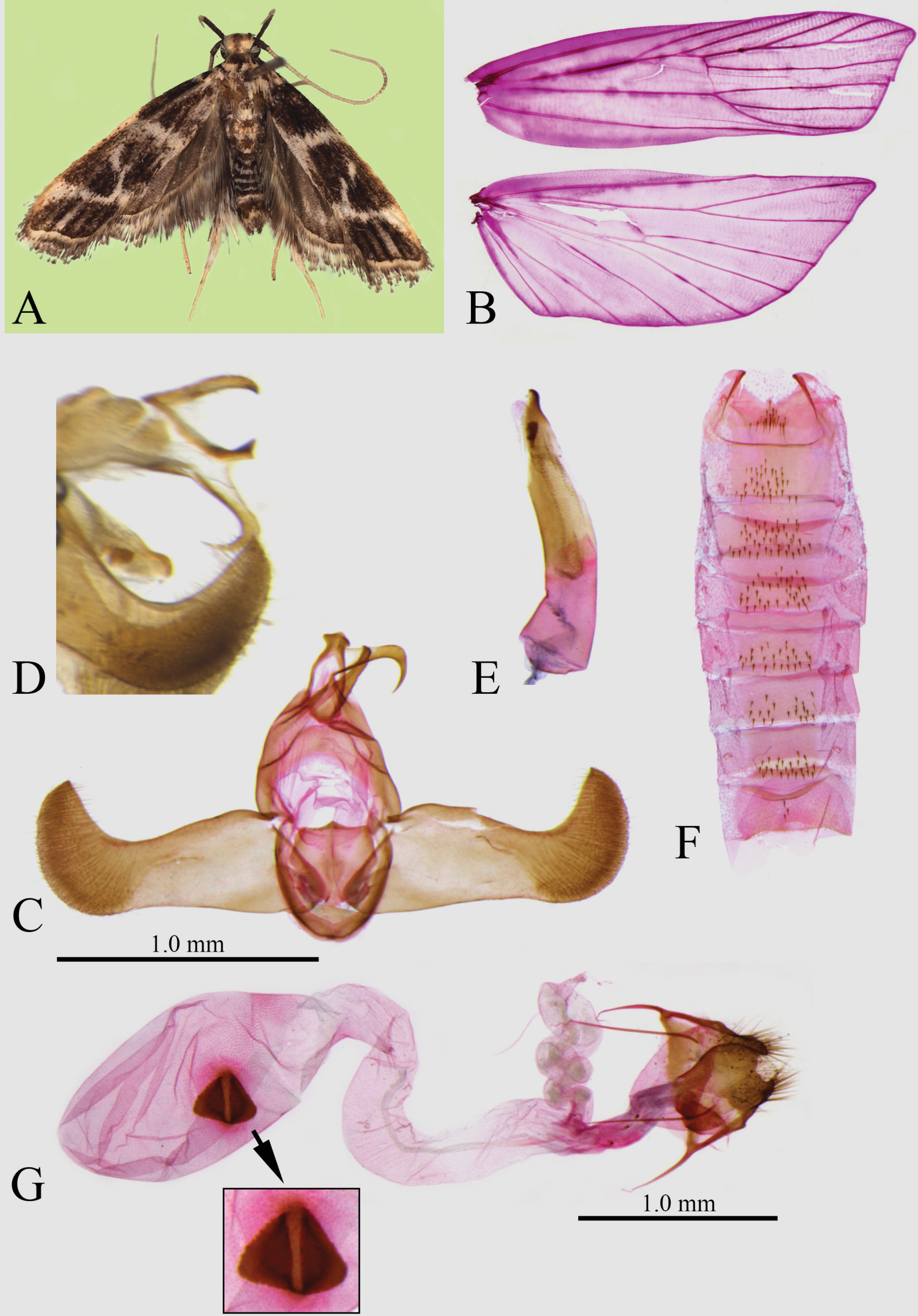

FIGURE 10. Dragmatucha ghanaensis Park, sp. nov.: A, adult, holotype; B, venation, paratype, wing slide no. CIS-7447; C, male genitalia, holotype, gen. slide no. CIS-7196; D, lateral view of uncus+gnathos; E, aedeagus; F, abdomen with spinous zones; G, female genitalia, paratype, with close-up signum, gen. slide no. CIS-7156. 
Distribution. Ghana (Central).

Etymology. The species name is derived from the name of the country of the type locality.

\section{Dragmatucha crinifrutalis Park, sp. nov.}

(Figs 11A-H)

Type material. Holotype: male, Uganda Western, Kibale Forest, Kanayawara 1520 m, 0³3'39'N 30²1'27"E, 22 x 2014, leg. D.J.L. Agassiz; gen. slide no. CIS-7197, in NHMUK. Paratypes: 1ô, Kibale Nat. Park, Biol. Field Station, 19-24 xi 2014, LF leg. W. Mey; gen slide no. CIS-7007; 2ð, same data as holotype; gen. slide no. CIS-7467; wing slide no. 7446; gen. slide no. CIS-7058; COI Barcode CBNU055 \& CBNU064, in MfN.

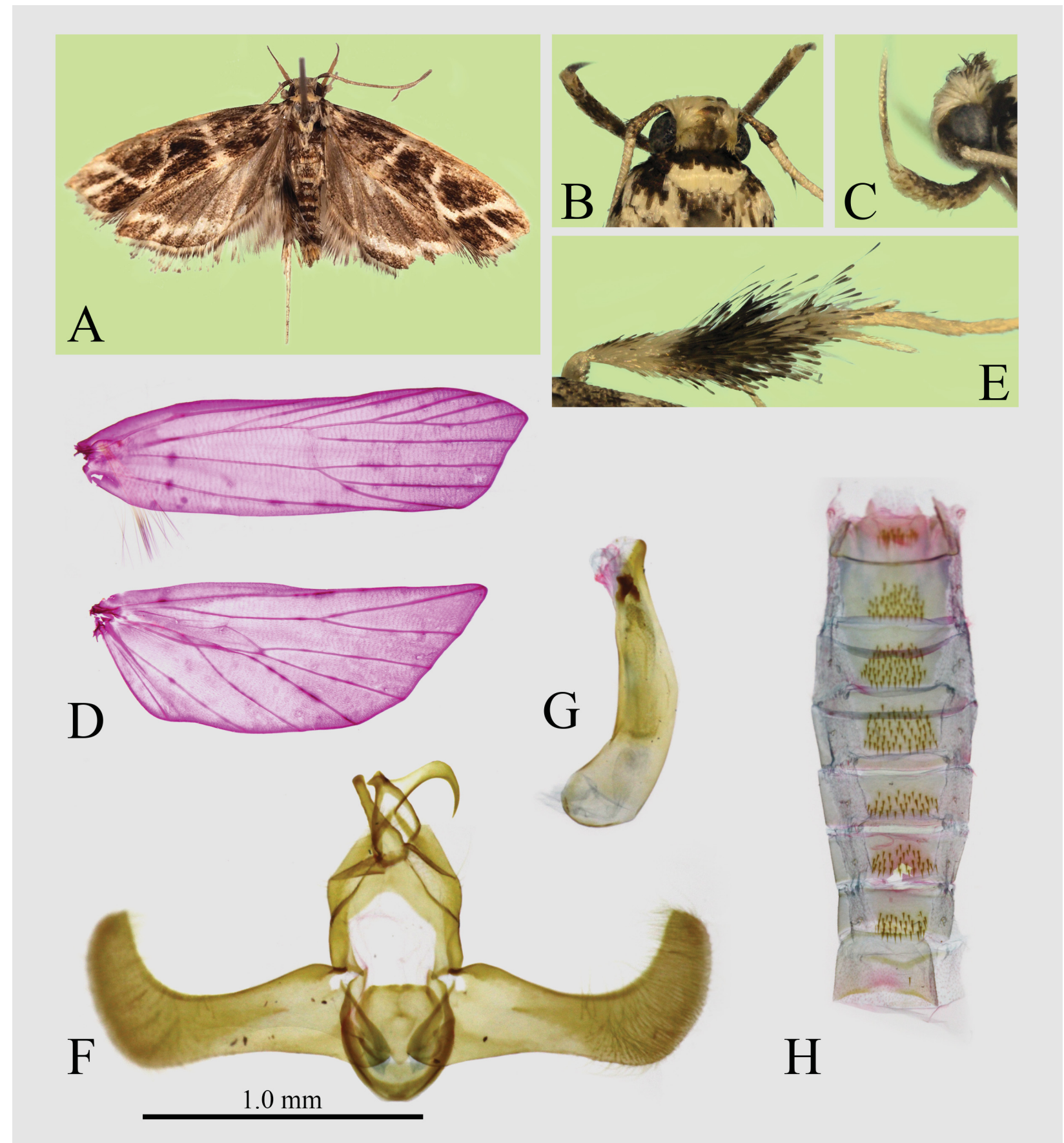

FIGURE 11. Dragmatucha crinifrutalis Park, sp. nov.: A, adult, paratype; B, head and thorax, dorsal view; C, labial palpus, lateral view; D, venation, wing slide no. CIS-7446; E, hind tibia; F, male genitalia, holotype, gen. slide no. CIS-7197; G, aedeagus; $\mathrm{H}$, abdomen with spinous zones. 
Diagnosis. Due to similar forewing pattern, this species resembles the preceding new species, D. ghanaensis sp. nov., but it can be distinguished by the forewing postmedian band which is less broadened anteriorly than in D. ghanaensis sp. nov., and the hind wing with differently developed CuP as noted in the following description. The male genitalia can be distinguished from the latter by the basal plate of the gnathos which is truncated apically, whereas in the latter it is pentagonal; valva more elongate, juxta with nearly straight caudal margin.

Description. Male (Figs 11A-E). Wingspan $15.0 \mathrm{~mm}$. Head: Yellowish white dorsally. Antenna slightly shorter than forewing; basal segment elongated, blackish all around; flagellum yellowish white throughout, without annulations, finely ciliate. Second palpomere of labial palpus thickened, arched, yellowish white, speckled with brown scales on outer surface, dark brown dorsally, yellowish white apically; $3^{\text {rd }}$ palpomere slender, strongly upturned, shorter than $2^{\text {nd }}$ palpomere, yellowish white, speckled with some dark brown scales. Thorax: Tegula yellowish white, speckled with dark fuscous scales anteriorly; thorax yellowish white dorsally. Hind tibia (Fig. 11E) white in basal $1 / 3$ and roughly scaled with dark yellowish-brown scales in distal $2 / 3$ all around. Forewing ground color yellowish brown; antemedian band yellowish white, nearly parallel-sided; a small crescent, yellowish white mark connects postmedian band by an oblique band; postmedian band oblique, slightly broadened at costa; costa slightly oblique beyond 3/4; apex more or less acute; termen oblique, slightly sinuate; fringe with narrow yellowish white basal line and yellowish brown median line, white distally; venation (Fig. 11D) similar to that of D. ghanaensis sp. nov. Hind wing ground color paler than forewing; postmedian band well-developed, yellowish white, strongly angled on vein $\mathrm{M}_{2}$; apex acute; venation with $\mathrm{M}_{2}$ well-developed; $\mathrm{M}_{3}$ entirely merged with $\mathrm{CuA}_{1}$; Cup uniquely developed, arising near base, arched in cell and crossing lower margin of cell at about middle. Abdomen (Fig. 11H): Spinous zones on dorsal surface broad, densely spiny; tergite VIII heavily sclerotized with crescent sclerite along anterior margin; sternite VIII concave on caudal margin.

Male genitalia (Figs 11F, G): Uncus rather short, reaching apex of basal plate of gnathos. Basal plate of gnathos truncated on caudal margin; median process large, strongly bent beyond middle, with sharply pointed apex. Tegumen weakly sclerotized, with concave anterior margin. Valva elongate, slightly narrowed toward cucullus; costa convex near base, then oblique; ventral margin gently concave; sacculus weakly developed, nearly invisible; cucullus more or less elongated, with slightly convex outer margin, densely setose; apex not sharply pointed. Juxta jar-shaped, with nearly straight caudal margin, lacking latero-caudal lobes; median vertical ridge not developed. Aedeagus as long as valva, narrowed toward apex, bent before middle, dorsal surface slightly produced, with Sshaped cornutus distally.

Female unknown.

Distribution. Uganda (Kibale Forest).

Etymology. This species name is derived from the Latin, crinis (= hair) and frutex (= tuft, bush), with a Latin suffix, -alis, referring to the rough piliform scale tuft of the hind tibia.

\section{Dragmatucha dizostera Park, sp. nov.}

(Figs 12A-G)

Type material. Holotype: male, Uganda, Mpigi, Mpanga Forest, 25-30 xi 2014, LF leg. W. Mey; gen. slide no. CIS-7468, in MfN.

Diagnosis. This species is also similar to the two preceding species in the forewing pattern, but it can be distinguished by the postmedian band being curved outwardly, reaching near tornus on inner margin, and followed by well-developed yellowish white transversal bands. The male genitalia are characterized by the large, horn-shaped uncus and the cucullus subtriangular with round apex.

Description. Male (Figs 12A, B). Wingspan $13.0 \mathrm{~mm}$. Head: Yellowish white dorsally, with yellowish brown scales centrally. Antenna shorter than forewing; basal segment elongated, dark brown all around; flagellum yellowish white throughout, without annulations. Second palpomere of labial palpus thickened, arched, dark brown on outer surface and dorsally, yellowish white at apex; yellowish white on inner surface and ventrally; $3^{\text {rd }}$ palpomere slender, strongly upturned, as long as $2^{\text {nd }}$ palpomere, yellowish white in basal half and dark brown in distal half dorsally. Thorax: Tegula creamy white, with blackish scales on anterior margin; thorax creamy white dorsally, with dark fuscous, oblique bands arising from middle and obliquely extended to lateral margins anteriorly. Hind tibia white in basal $1 / 3$ and with dark yellowish-brown piliform scales in distal $2 / 3$ all around, mixing with white scale 


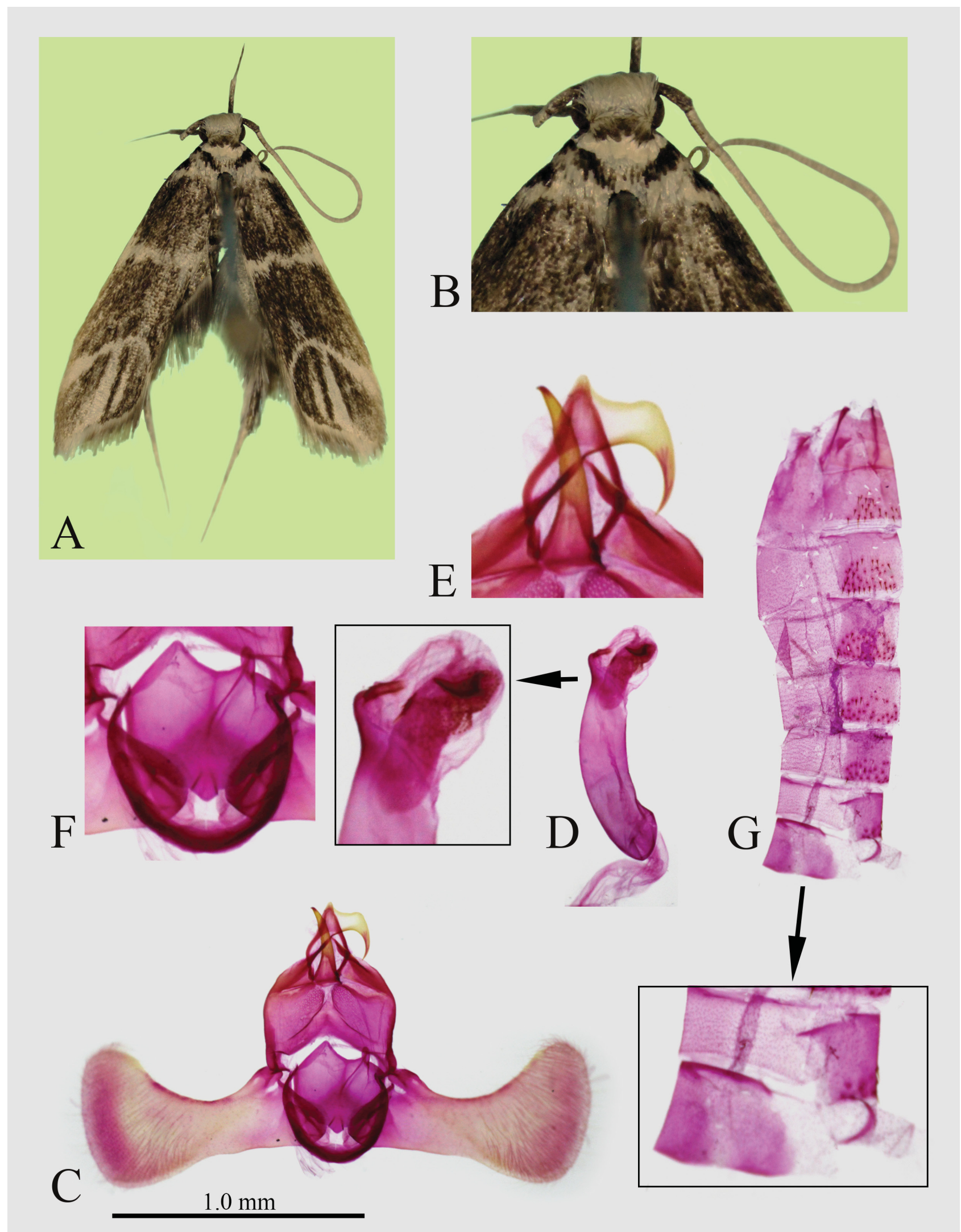

FIGURE 12. Dragmatucha dizostera Park, sp. nov.: A, adult, holotype; B, head, dorsal view; C, male genitalia, holotype, gen. slide no. CIS-7468 D, aedeagus, with close-up apical part; E, close-up uncus+ gnathos; F, close-up juxta; G, abdomen with spinous zones. 
distally. Forewing ground color yellowish brown; black at base, with creamy white sub-basal streak; antemedian band narrow, yellowish white, nearly parallel sided, zigzagged margins; postmedian band narrow, strongly curved at middle inwardly, arising from costa and reaching near tornus on inner margin, gradually broadened toward costa beyond middle; two yellowish white transverse bands well-developed beyond postmedian band: upper one longer and broader, reaching termen; lower one shorter, not reaching termen; apex more or less acute; termen slightly concave beyond apex; fringe yellowish white beyond apex to anterior $1 / 3$ of termen, then yellowish brown with yellowish white basal line in posterior $2 / 3$. Hind wing yellowish brown; postmedian band yellowish white, arising from $3 / 4$ of costa to vein $\mathrm{M}_{2}$. Abdomen (Fig. 12G): Spinous zones on dorsal surface broad, densely spiny; tergite VIII with heavily sclerotized, crescent sclerite along anterior margin; sternite VIII not modified.

Male genitalia (Figs 12C-F): Uncus large, horn-shaped, with acute apex. Basal plate of gnathos triangular in distal part, with acute apex; median process large, broad in basal half, strongly bent beyond middle, with sharply pointed apex. Tegumen weakly sclerotized, gently concave on anterior margin. Valva narrowed medially; costa convex near base, then oblique; ventral margin nearly straight before ventral margin of cucullus; sacculus weakly developed, triangular basally; cucullus subtriangular, expanded in lower corner, slightly convex on outer margin, densely setose; apex rounded. Juxta jar-shaped, widest at middle, then narrowed distally, concave on caudal margin, slightly produced in triangular latero-caudally; median vertical ridge weakly developed; triangularly protruded at middle on anterior margin. Aedeagus slender, nearly parallel-sided, slightly shorter than valva.

Female unknown.

Distribution. Uganda (Mpigi).

Etymology. This species name is derived from the Greek, dis (= double) and zoster (= belt), referring to the two transversal stripes in distal part of forewing.

\section{Dragmatucha kakumensis Park, sp. nov.}

(Figs 13A-E)

Type material. Holotype: female, Ghana, Western Region, Kakum Forest, Visitors' Centre, 19 xi 2011, leg. L. Aarvik \& L.O. Hansen; gen. slide no. CIS-7198; Wing slide no. CIS-7464; COI barcode CBNU086, in NHMO. Paratype: 1 , , Central Kakum N. P. 150 m, $5^{\circ} 20^{\prime} 54^{\prime \prime N} 1^{\circ} 23^{\prime} 7 " \mathrm{~W}, 19$ xi 2011, leg. D.J.L. Agassiz; gen. slide no. CIS7199; COI barcode CBNU101, in NHMUK.

Diagnosis. The forewing pattern of this new species is similar to all species of the hispidula species-group, and the venation of both wings are well accordant with the type species of the genus. The species can be distinguished from its congeners by the forewing markings, especially the peanut-shaped, dark brown zone between postmedian band and termen.

Description. Female (Figs 13A, C). Wingspan $12.0 \mathrm{~mm}$. Head: Yellowish white dorsally, with dark brown scales centrally. Antenna as long as forewing; basal segment elongated, dilated distally, dark brown all around; flagellum yellowish white throughout, without annulations. Second palpomere of labial palpus thickened, dark brown speckled with yellowish white scales dorsally, yellowish white ventrally at apex; yellowish white on inner surface; $3^{\text {rd }}$ palpomere slender, strongly upturned, shorter than $2^{\text {nd }}$ palpomere, yellowish white at base and beyond $3 / 4$, speckled with dark brown scales medially. Thorax: Tegula yellowish white in anterior half and dark brown in posterior $1 / 3$; thorax densely covered with dark brown scales dorsally, yellowish white scales laterally. Hind tibia yellowish white with dark yellowish-brown piliform scales medially. Forewing ground color dark yellowish brown, with dark brown basal streak; sub-basal band yellowish white; antemedian band narrow, yellowish white, nearly parallel sided, zigzagged margins; a crescent, oblique streak near end of discal cell; postmedian band narrow, yellowish white, slightly broadened at costa; area between postmedian band and termen more or less peanut-shaped, dark brown; costa slightly arched in basal $1 / 3$ and near $2 / 3$, then oblique; apex produced; termen slightly concave beyond $\mathrm{M}_{1}$; venation (Fig. 13C): distance between origins of $\mathrm{R}_{1}$ and $\mathrm{R}_{2}$ about $4 x$ of $\mathrm{R}_{2}$ and $\mathrm{R}_{3} ; \mathrm{R}_{3}$ arising from near upper corner of discal cell, stalked with $R_{4+5}$ for basal 1/3; $R_{5}$ reaching costa; $M_{1}$ remote from $R_{3+4}$ at base; $M_{2}$ arising from lower corner of cell; $\mathrm{M}_{3}$ entirely merged to $\mathrm{CuA}_{1} ; \mathrm{CuA}_{1}$ short-stalked with $\mathrm{CuA}_{2} ; 1 \mathrm{~A}+2 \mathrm{~A}$ not forked; cell weakly closed. Hind wing of same ground color as forewing, with narrow, yellowish white postmedian band, sharply angled on vein $\mathrm{M}_{2}$; apex produced; termen sinuate; fringe with yellowish white basal line; venation with $\mathrm{M}_{2}$ well-developed; $\mathrm{M}_{3}$ entirely merged with $\mathrm{CuA}_{1} ; \mathrm{CuA}_{2}$ arising from near lower corner of discal cell; Cup well- 
developed, arising from near base of wing. Abdomen (Fig. 13E): Spinous zones on dorsal wall with scattered spines; tergite VIII convex on caudal margin

Female genitalia (Fig. 13D): Apophyses anteriores about 2/5 length of apophyses posteriors. Ostium bursae with irregularly sclerotized plates laterally. Antrum membranous, weakly developed. Ductus bursae narrowed between antrum and ductus bursae. Ductus bursae about 2x length of corpus bursae, broadened in posterior half; ductus seminalis arising from broadened median part of ductus bursae. Corpus bursae large, ovate; signum plate with broad median furrow; upper and lower plate nearly symmetrical, with dense conic spines.

Male unknown.

Distribution. Ghana (Kakum).

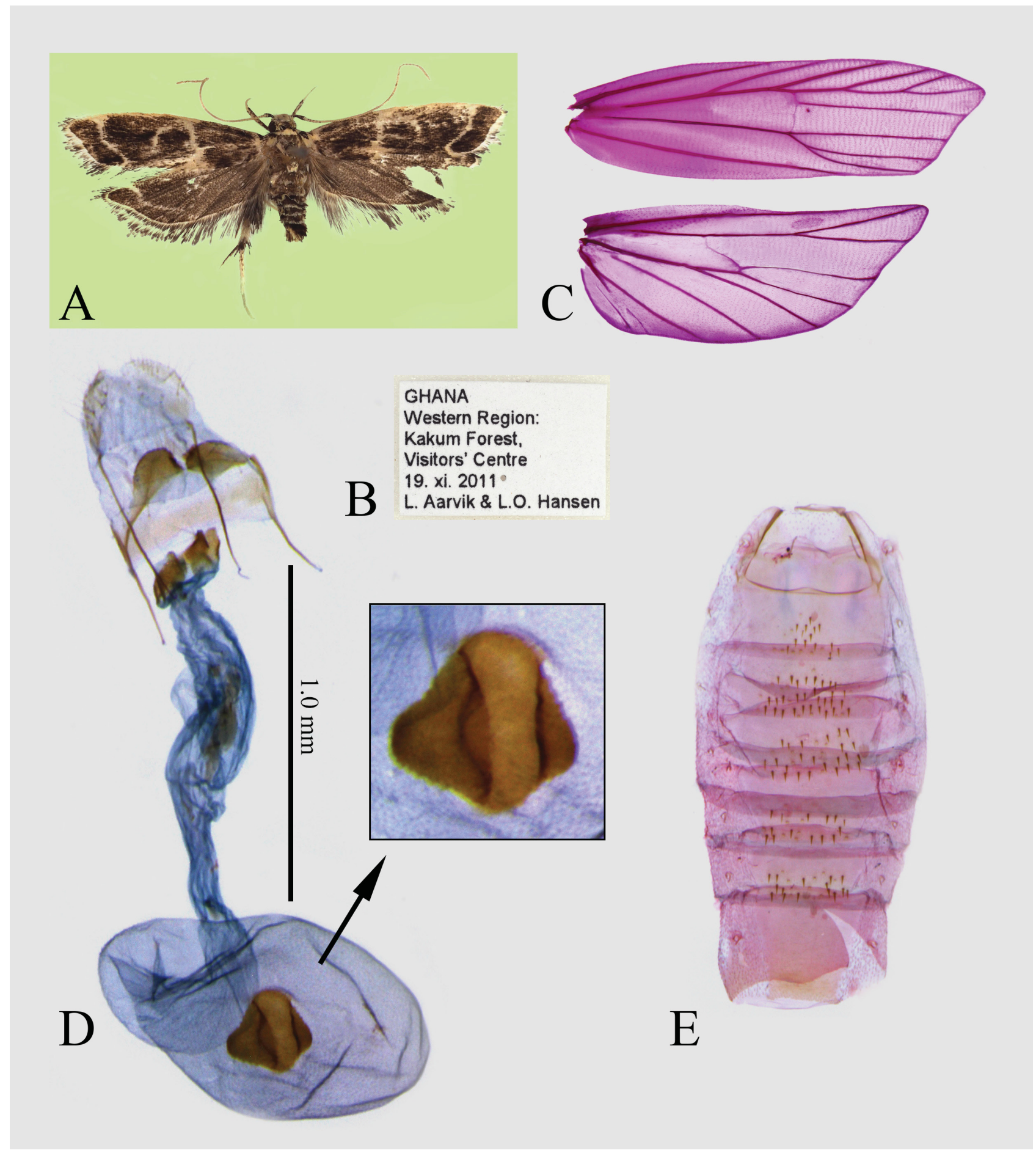

FIGURE 13. Dragmatucha kakumensis Park, sp. nov.: A, adult, holotype; B, label; C, venation, wing slide no. CIS-7464; D, female genitalia, paratype, with close-up signum, gen. slide no. CIS-7199; E, abdomen, with spinous zones. 
Etymology. This species' name is derived from the type locality.

Remarks. The analysis of the COI sequence places the present species far from the other species. However, it is no doubt that the species belongs to the genus Dragmatucha by morphological characters, including the wing color pattern and the venation of both wings. Further study is required for clarifying this issue.

\section{Acknowledgements}

We would like to express our cordial thanks to W. Mey, Museum für Naturkunde, Berlin, Germany, and John E. Rawlins and Chen W. Young, Invertebrate Zoology, Carnegie Museum of Natural History, Pittsburgh, USA, for the loan of material collected in Africa. We are indebted to W. De Prins and S. Kerkhof, Royal Belgian Institute of Natural Sciences, Brussels, Belgium, for arranging the loan of specimens from the Royal Museum of Central Africa, Tervuren; and to S. W. Cho and W. De Prins for their helpful comments which greatly improved the quality of the manuscript. Likewise the two reviewers gave important contributions to the manuscript for which we are very grateful. Especially we thank the Zootaxa editor, Carlos Mielke, for his generous assistance in aiding this manuscript through the publication process and also for valuable input to the manuscript. This research was supported by Basic Science Research Program through the National Research Foundation of Korea (NRF) funded by the Ministry of Education (MSIT) (2018R1D1A1B07042503).

\section{References}

Janse, A.J.T. (1954) Gelechiidae. In: Janse, A.J.T. (Ed.), The moths of South Africa. 5 (4). Caxton Limited, Pretoria, pp. $350-$ 382.

Kornerup, A. \& Wanscher, J.H. (1978) Methuen Handbook of Colour. $2^{\text {nd }}$ Edition. Methuen \& Co., London, 252 pp.

Meyrick, E. (1908) Descriptions of African Micro-Lepidoptera. Proceedings of the Zoological Society of London, 47, 716756. https://doi.org/10.1111/j.1469-7998.1908.tb07404.x

Meyrick, E. (1925) Lepidoptera Heterocera Fam. Gelechiadae. In: Wytsman, P. (Ed.), Genera Insectorum. Fascicule 184. V. Verteneuil \& L. Desmet, Imprimeurs-Éditeurs, Bruxelles, pp. 1-290, pls 1-5.

Park, K.-T. (2018) A new genus Thubdora Park, sp. nov. and seven new species of the subfamily Torodorinae (Lepidoptera, Lecithoceridae) from Africa. Journal of Asia-Pacific Entomology, 21, 1085-1093. https://doi.org/10.1016/j.aspen.2018.07.018

Park, K.-T. \& De Prins, W. (2019) A review of the Lecithoceridae (Lepidoptera: Gelechioidea) of southern Africa, based on type specimens deposited in the Ditsong National Museum of Natural History (TMSA), with descriptions of three new species. Zootaxa, 4623 (1), 61-89. https://doi.org/10.11646/zootaxa.4623.1.5

Park, K.-T., Mey, W., Koo, J.M., De Prins, J. \& Cho, S. (2019) Revision of the genus Ptilothyris Walsingham, 1897 (Lepidoptera: Gelechioidea: Lecithoceridae), with descriptions of eight new species from Africa. Zootaxa, 4567 (2), 201-235. https://doi.org/10.11646/zootaxa.4567.2.1

Pinhey, E.C.G. (1975) Moths of southern Africa. Descriptions and colour illustrations of 1183 species. Tafelberg Publishers, Cape Town, 273 pp., 63 pls.

Walsingham, T.G. (1881) On the Tortricidae, Tineidae and Pterophoridae of South Africa. Transactions of the entomological Society of London, 1881 (2), 219-288, pls. 10-13.

Walsingham, T.G. (1891) African Micro-Lepidoptera. Transactions of the entomological Society of London, 1891, 63-132. https://doi.org/10.1111/j.1365-2311.1891.tb01643.x 
APPENDIX 1. Barcode sequence data for nine species of Dragmatucha, with our own sequence identification log number (CBNU-\#) to match the specimen sequenced.

Dragmatucha kabarolensis, CBNU087 (-/1n)

AACATTATATTTTATTTTTGGAATTTGAAGAGGGATAATTGGGACTTCTTTAAGACTTTTAATTCGGGCAGAATTAGGAAATCCAGGCTCTTTAATTGGAGATGATCAAATTTATAATACTATTGTTACAGCTCATGCTTTTATTATAATTTTTTTTATAGTAATACCTATTATAATTGGGGGATTTGGGAATTGACTTGTTCCTTTAATATTAGGGGCTCCTGATATAGCTTTCCCCCGTATAAATAATATAAGATTTTGATTATTACCCCCTTCTTTACTATTATTAATTTCAAGAAG AATTGTAGAAAATGGAGCTGGTACAGGTTGAACAGTTTACCCCCCTTTATCTTCAAATATTGCACATAGGGGAAGATCCGTTGATTTAGCTATTTTTTCTTTACATTTAGCCGGAATTTCTTCTATTTTAGGGGCAATTAATTTTATTACCACTATTATTAATATACATCTTTATAATATAAATTTTGATCAAATACCTTTATTTGTTTGAGCTGTAGGAATTACTGCTTTACTTTTACTTTTATCTTTACCTGTTTTAGCTGGGGCTATTACTATATTATTAACTGATCGTAATATTAA TACATCATTTTTTGATCCTGCAGGGGGAGGAGATCCTATTCTTTATCAACATTTATTT

Dragmatucha galbinea, CBNU084 (-/1n)

AACATTATAT TT TAT T T T GGAATTTGA GCA GGAATAATTGGAACTTCTTTAAGACTTTTAATCCGGGCAGAATTA GGGAATCCTGGCTCTTTAATTGGA GATGACCAAATTTATAATACTATTGTTACCGCTCATGCTTTTATTATAATTTTTTTTATAGTTATACCTATTATAATTGGGGGATTTGGGAATTGACTTG TTCCCCTAATATTAGGAGCCCCTGATATAGCTTTCCCTCGTATAAATAATATAAGATTTTGACTTTTACCCCCCTCATTACTTTTACTGATTTCAAGAAGAATTGTTGAAAATGGAGTAGGTACTGGTTGGACAGTTTACCCCCCTTTATCTTCTAATATTGCCCATAGAGGAAGTTCTGTTGATTTAGCTATTTTTTCCCTACATTTAGCAGGAATTTCTTCTATTTTAGGGGCAATTAATTTTATTACTACTATTATTAATATACGTCTTTTTAACATAAATTTTGATCAAATACCTTTATTTGTTTGAGCTGTAGGAATTACTACTTTACTCTTACTTTTATCTTTACCTGTTTTAGCCGGAGCTATTACTATATTATTAACTGATCGAAACATTAATACATCATTTTTTGACCCTGCCGGAGGGGGAGACCCTATTTTATACCAACATTTATTT

Dragmatucha saltualis, CBNU088 (-/1n)

TACACTATATTTTATTTTTGGGATTTGAGCAGGTATAATTGGAACTTCTTTAAGACTTTTAATTCGTGCTGAATTAGGTAACCCCGGATCTTTAATTGGAGATGATCAAATTTATAATACTATTGTAACAGCTCATGCTTTCATTATAATTTTTTTTATAGTAATGCCTATTATAATTGGGGGATTTGGAAATTGACTTGTACCTCTAATACTTGGAGCTCCTGATATAGCTTTCCCCCGTATAAATAATATGAGATTTTGACTTTTACCTCCTTCTCTTTTATTGTTAATTTCAAGAAG AATTGTAGAAAATGGAACAGGAACAGGATGAACTGTGTACCCCCCCTTATCTTCTAATATTGCTCACAGAGGTAGATCAGTAGATTTAGCTATTTTTTCTCTTCATTTAGCTGGAATTTCTTCTATTTTAGGGGCTATTAATTTTATTACCACAATTATTAACATGCGTCTTTATAATATAAATTTTGACCAAATACCTTTATTTGTTTGAGCAGTAGGTATTACTGCTTTACTCTTACTTTTATCTCTCCCCGTTTTAGCTGGGGCTATTACTATATTACTTACTGATCGTAATATTAA TACCTCATTTTTTGACCCTGCTGGGGGAGGAGATCCAATTCTTTATCAACATTTATTT

Dragmatucha vittatella, CBNU018 (0-0.5\%/2n)

AACATTATATTTTATTTTTGGAATTTGAGCAGGAATAATTGGAACTTCTTTAAGACTTTTAATCCGAGCAGAATTAGGAAATCCTGGTTCTTTAATTGGAGATGATCAAATTTATAATACTATTGTTACAGCTCATGCTTTTATTATAATTTTTTTCATAGTTATACCTATTATAATTGGAGGATTTGGAAATTGATTAGTTCCTTTAATACTAGGAGCCCCTGATATAGCTTTTCCTCGTATAAATAATATAAGGTTCTGACTTTTACCTCCTTCATTACTTTTATTAATTTCAAGAAG AATTGTTGAAAATGGTGCTGGCACTGGTTGAACAGTTTATCCCCCATTATCTTCTAATATTGCCCACAGAGGAAGTTCTGTTGATTTAGCTATTTTTTCTTTACATTTAGCAGGAATTTCTTCTATTTTAGGAGCAATTAATTTTATTACTACTATTATTAATATACGTCTTTTTAACATAAATTTTGATCAAATACCATTATTTGTTTGGGCTGTAGGAATTACTGCTCTACTTTTACTTTTATCTTTACCTGTTTTAGCTGGTGCTATTACTATATTATTAACTGATCGTAATATTAA TACATCATTTTTTGATCCTGCTGGAGGGGGAGATCCTATTTTATACCAACATTTATTT

Dragmatucha cochliana, CBNU083 (-/1n)

AACTTTATATTTTATTTTTGGAATTTGAGCAGGAATAATTGGAACTTCTTTAAGACTTTTAATTCGAGCAGAATTAGGAAATCCAGGCTCTTTAATTGGAGATGACCAAATTTATAATACTATTGTTACAGCTCATGCTTTTATTATAATTTTTTTTATAGTTATACCTATTATAATTGGAGGATTTGGTAATTGACTTGTTCCATTAATATTAGGAGCTCCT- 
GATATAGCTTTCCCCCGAATAAATAATATAAGATTTTGACTTTTACCTCCTTCATTATTTTTATTAATTTCAAGAAG AATCGTTGAAAATGGTGCTGGTACTGGTTGAACAGTTTATCCTCCTTTATCATCTAATATTGCTCATAGAGGAAGTTCTGTTGATTTAGCTATTTTCTCCTTACATTTAGCAGGTATTTCTTCTATTTTAGGGGCAATTAATTTTATTACTACTATTATTAATATACGTCTTTTCAGAATAAATTTTGATCAAATACCTTTATTTGTTTGAGCTGTAGGAATTACTGCTTTACTTCTTCTTTTATCTTTACCTGTATTAGCTGGAGCTATTACTATATTATTAACTGATCGTAATATTAA TACATCATTTTTTGATCCTGCAGGAGGAGGAGATCCTATTCTTTATCAACATTTATTT

Dragmatucha pedalis, CBNU102 (0-0.6\%/3n)

TACATTGTATTATATTTTTGGAATGTGAGCAGGTATAATTGGAACCTCTTTAAGACTTTTAATTCGAGCAGAATTAGGAAACCCTGGTTCCTTAATTGGAGATGACCAAATTTATAATACTATTGTTACAGCTCATGCTTTTATTATAATTTTTTTTATAGTTATACCCATTATAATTGGAGGGTTTGGAAATTGACTTGTTCCTTTAATATTAGGAGCTCCTGATATAGCTTTCCCACGCATAAATAATATAAGATTTTGACTTTTACCTCCTTCTTTAATTTTATTAATTTCAAGAAG AATTGTAGAAAATGGAGCAGGTACAGGTTGAACAGTTTACCCTCCCTTATCTTCTAATATTGCTCATAGAGGTAGATCAGTTGATTTAGCTATTTTTTCTTTACATTTAGCAGGAATTTCTTCTATTTTAGGTGCTATTAACTTTATTACCACTATTATTAATATACGTCTTTTTAATATAAATTTTGATCAAATACCTTTATTTGTTTGAGCAGTAGGAATTACTGCTTTACTTTTACTTTTATCTTTACCTGTTTTAGCTGGTGCTATTACTATATTATTAACTGATCGTAATATTAA TACATCATTTTTTGACCCTGCTGGAGGGAGAGACCCTATTCTTTACCAACATTTATTT

Dragmatucha ghanaensis, CBNU103, $(0-0.5 \% / 2 \mathrm{n})$

AACATTATATTTTATTTTTGGAATTTGAGCAGGAATAATTGGAACTTCACTAAGACTTTTAATTCGAGCAGAATTAGGAAATCCAGGTTCTTTAATTGGGGACGATCAAATTTATAATACTATTGTTACAGCTCATGCTTTTATTATAATTTTTTTTATAGTTATACCTATTATAATTGGAGGATTTGGTAATTGACTTGTTCCCTTAATATTAGGAGCTCCTGATATAGCTTTCCCTCGTATAAACAATATAAGATTTTGACTTTTACCCCCCTCTTTACTTTTACTAATTTCAAGAAG AATTGTAGAAAATGGAGCTGGTACAGGTTGAACAGTTTACCCTCCTTTATCATCAAATATTGCTCATAGAGGAAGATCAGTAGATTTAGCTATTTTCTCATTACATTTAGCTGGAATTTCTTCTATTCTAGGAGCTATTAATTTTATTACTACTATTATTAATATACGTCTTTATAATATAAATTTTGATCAAATACCTTTATTTGTTTGAGCCGTAGGTATTACTGCTTTACTTTTACTTTTATCTCTTCCAGTTTTAGCAGGCGCTATTACTATATTATTAACTGACCGTAATATTAACACTTCATTTTTTGATCCAGCTGGAGGTGGGGATCCTATTCTCTATCAACATTTATTT

Dragmatucha crinifrutalis, CBNU064 (0-0.3\%/2n)

AACATTATATTTTATTTTTGGAATTTGAGCAGGAATAATTGGAACTTCCTTAAGACTTTTAATTCGAGCAGAATTAGGAAACCCAGGTTCTTTAATCGGAGATGATCAAATTTATAATACTATTGTTACAGCTCACGCTTTTATTATAATTTTTTTTATAGTTATACCTATTATAATTGGGGGATTTGGTAATTGACTTGTTCCTTTAATATTAGGGGCTCCTGATATAGCTTTCCCTCGTATAAATAACATAAGATTCTGACTTTTGCCTCCTTCTTTACTTTTATTAATTTCAAGAAG AATTGTAGAAAATGGAGCTGGTACAGGCTGAACAGTTTACCCTCCTCTATCTTCTAATATTGCTCATAGAGGAAGATCAGTAGATTTAGCTATTTTCTCATTACATTTAGCTGGAATTTCCTCTATTTTAGGGGCTATTAACTTTATTACTACTATTATTAATATACGTCTTTATAATATAAATTTTGATCAAATACCTTTATTTGTTTGAGCTGTAGGTATTACTGCTTTACTTTTACTTTTATCTCTTCCAGTTTTAGCGGGTGCTATTACTATATTATTAACTGATCGTAATATCAA TACCTCATTTTTTGATCCTGCCGGAGGGGGAGACCCTATTCTTTATCAACATTTATTT

Dragmatucha kakumensis, CBNU086 (0-0.2\%/2n)

AACATTATATTTCATTTTTGGAATTTGAGCTGGAATAATTGGAACTTCTTTAAGATTATTAATTCGAGCAGAACTAGGAAATCCTGGTTCTTTAATTGGAGATGATCAAATTTATAATACTATTGTTACAGCTCATGCCTTTATTATAATTTTTTTTATAGTAATACCTATTATAATTGGAGGATTTGGAAATTGATTAGTTCCTTTAATACTTGGTGCCCCTGATATAGCTTTCCCCCGAATAAATAATATAAGATTTTGACTTTTACCTCCTTCTCTTCTTCTTTTAATTTCAAGAAG AATTGTTGAAAATGGAGCTGGTACTGGTTGAACAGTTTATCCTCCACTATCTTCTAATATTGCACATAGAGGAAGTTCAGTTGATTTAGCCATTTTTTCTTTACATTTAGCTGGAATTTCCTCTATTTTAGGGGCTATTAATTTTATTACTACTATTATTAATATACGTCTTTATAATATAAATTTTGATCAAATACCTTTATTTGTTTGAGCAGTAGGCATCACTGCTTTACTTTTACTTTTATCTTTACCTGTTTTAGCTGGTGCTATTACTATATTATTAACAGATCGTAATATTAA TACTTCTTTTTTTGACCCGGCTGGAGGGGGAGATCCTATTCTTTATCAACATTTATTT 